\title{
$C_{0} \mathbf{I} \cdot \mathbf{R}^{\circ} \mathbf{P} \cdot \mathrm{E} \cdot \mathrm{E}$
}

Centre Interuniversitaire sur le Risque, les Politiques Économiques et l'Emploi

Cahier de recherche/Working Paper 10-48

\section{Resolution of Financial Distress under Chapter 11}

\author{
Amira Annabi \\ Michèle Breton \\ Pascal François
}

Décembre/December 2010

Annabi: HEC Montréal

Breton: HEC Montréal and GERAD. Correspondence to: Michèle Breton, HEC Montréal, 3000 Côte-SainteCatherine, Montréal (QC), Canada H3T 2A7

michele.breton@hec.ca

François: HEC Montréal and CIRPÉE

We would like to thank Jan Ericsson, Jean Helwege and Franck Moraux for their useful comments. We also thank Ali Boudhina for excellent research assistance. Annabi and Breton acknowledge financial support from IFM ${ }^{2}$ and NSERC. François acknowledges financial support from SSHRC. 


\begin{abstract}
:
We develop a contingent claims model of a firm in financial distress with a formal account for renegotiations under the Chapter 11 bankruptcy procedure. Shareholders and two classes of creditors (senior and junior) alternatively propose a reorganization plan subject to a vote. The bankruptcy judge can intervene in any renegotiation round to impose a plan. The multiple-stage bargaining process is solved in a non-cooperative game theory setting. The calibrated model yields liquidation rate, Chapter 11 duration and percentage of deviations from the Absolute Priority Rule that are consistent with empirical evidence.
\end{abstract}

Keywords: Credit risk, Chapter 11, game theory, dynamic programming

JEL Classification: C61, C7, G33, G34 


\section{Introduction}

A corporation in financial distress can either negotiate privately with its claimants or file under the protection of the legal bankruptcy procedure. The recent bailouts of some major U.S. companies during the latest crisis has emphasized the complex and critical impact that the bankruptcy procedure can have on the economy as a whole. In the U.S., Chapter 11 of the bankruptcy Code presents an alternative to the liquidation of a bankrupt firm by defining a judicial context in which the firm can reorganize its activities in order to emerge as a viable entity. Over the last few years, Chapter 11 has become the dominant mode of resolution of financial distress for large public companies. Among the 213 bond defaults recorded by Moody's from 1997 to 2005, Davydenko (2010) documents that 54\% of them are technical defaults (i.e. missed payment), while $37 \%$ are resolved through Chapter 11, with only $9 \%$ of defaults being resolved out of Court. These figures highlight the need for a better understanding of the bankruptcy mechanism.

The aim of this paper is to formally model the characteristics of Chapter 11 negotiation and to analyze the determinants of reorganization outcomes. Specifically, we model the strategic interaction between claimants in Chapter 11 as a multiple-stage bargaining process, and solve it in a non-cooperative game theory setting. Our paper adds to the earlier literature by modeling a complex and realistic negotiation process, that incorporates different features of Chapter 11. In particular, we consider two classes of creditors with different seniorities and allow claimants to sequentially propose reorganization plans. Shareholders benefit from the exclusivity period that allows them to propose the first plan. One of these plans can be confirmed by the bankruptcy judge if all claimants agree on its implementation. We also account for Chapter 11 cramdown provision which allows the judge to impose a reorganization plan, thereby putting an end to a lengthy and costly negotiation. Furthermore, the bankruptcy judge has the opportunity to impose her own reorganization plan. Finally, our model respects the rule of automatic stay of assets as creditors are not allowed to liquidate parts of the assets as negotiations move from one round to another.

Our game-theoretic approach determines for each renegotiation round the possible equi- 
libria (liquidation, reorganization, or continuation to the next round) for every possible asset value. By specifying a standard diffusion process for asset value, we associate a probability to each of these equilibria, which yields a probabilistic representation of the Chapter 11 procedure with formal bargaining.

In line with empirical evidence, our model can generate several rounds of bargaining. Ongoing negotiations are driven by claimholders' uncertainty about judge behavior. Depending on firm asset value, the class of claimants, which proposes a reorganization plan, can have an incentive to narrow the chances of unanimous acceptance and hope for the judge to impose terms that are more favorable to them.

Once the model is calibrated on characteristics of firms entering Chapter 11 as well as on the bankruptcy timeline and costs, it replicates stylized facts about liquidation rates, time spent under Chapter 11, and frequency of deviations from the Absolute Priority Rule (APR).

The remainder of the paper is organized as follows. After a brief review of the related literature in section 2, we formally introduce the negotiation process under Chapter 11 in section 3. In section 4, we solve the game by backward induction and characterize the possible equilibrium outcomes. Section 5 presents the data and calibration method used to implement the model numerically. Model results are analyzed and compared to empirical evidence in section 6 . Section 7 concludes.

\section{Related literature}

Early contingent claims models of corporate debt assimilate default with immediate liquidation (Merton, 1974, Leland, 1994). The modelling of financial distress has primarily focused on out-of-Court renegotiations. Anderson and Sundaresan (1996) and Mella-Barral and Perraudin (1997) analyze strategic debt service, i.e. coupon reductions that shareholders can impose to creditors every time the firm is close to default. Mella-Barral (1999) study private debt renegotiations when shareholders and creditors can alternatively make takeit-or-leave-it offers. Fan and Sundaresan (2000) view renegotiations as a cooperative Nash 
bargaining game in which claimholders maximize renegotiations surplus to avoid costly liquidation. However, the assumption of a cooperative game for renegotiations may be harder to sustain for Chapter 11. Indeed, Brown (1989) and Gertner and Scharfstein (1991) argue that firms in default will cease private renegotiations and file bankruptcy when hold out problems are severe. Gilson, John and Lang (1990) as well as Datta and Iskandar-Datta (1995) provide empirical support for this view.

Bruche and Naqvi (2010) explicitly account for an agency conflict during financial distress between shareholders and creditors, as the former decide on the time to default while the latter decide on the time to liquidate. As acknowledged by these authors, this framework is best suited for creditor-friendly bankruptcy procedures. In Chapter 11, the judge is influential in preserving the going-concern value of the firm.

Hege and Mella-Barral (2005) and Hackbarth, Hennessy and Leland (2007) enrich the renegotiation framework by allowing for multiple creditors. Both works examine exchange offers proposed by shareholders. In Hackbarth, Hennessy and Leland (2007), one class of debt is bank debt and assumed to be renegotiable. The other is market debt, cannot be renegotiated, but allows the firm to increase its debt capacity.

More recent are the contributions which aim at capturing Chapter 11 specificity into the modelling of financial distress. Moraux (2002), François and Morellec (2004), Galai, Raviv and Wiener (2007), and Broadie, Chernov and Sundaresan (2007) assume that liquidation after Chapter 11 is triggered by the excursion of asset value beneath a default threshold. In these works however, the role of the judge is not taken into account. But, as documented by Chang and Schoar (2008), the influence of the judge on Chapter 11 outcomes is far from neutral.

From a different methodological standpoint, various classification models have been applied to the bankruptcy procedure. For instance, Luther (1998) uses artificial neural networks to predict Chapter 11 outcome. These works relate the likelihood of liquidation vs. reorganization to the financials of defaulting firms, but again, they fail to acknowledge procedural aspects (including the role of the judge) as a key determinant of corporate 
restructuring.

\section{The negotiation process model under Chapter 11}

Our modelling needs to be consistent with the main features of the Chapter 11 procedure. In the vast majority of cases, the firm in default files under Chapter 11 on a voluntary basis (see e.g. White, 1996, for evidence). As a result, the management team stays in place after filing, and enjoys an exclusivity period during which it can propose the first reorganization plan. ${ }^{1}$ Acceptance of the plan is subject to a vote among classes of claimholders. The judge observes the process and can either validate the plan if unanimously accepted, call for another round of renegotiations if unanimous consent is not achieved, or pronounce firm liquidation if reaching an agreement becomes unlikely. The judge may also use the cramdown provision, which allows her to impose a reorganization plan when she believes the procedure is getting too lengthy and costly. ${ }^{2}$ In practice, successfully reorganized firms may need more than one reorganization plan (see e.g. Carapeto, 2005).

Shareholders and creditors bargain over a sharing rule for asset value. The rule of automatic stay prevents creditors to seize assets during renegotiations. Hence the dynamics of asset value is not subject to partial liquidations (also known as "asset stripping"). ${ }^{3}$ We assume that all claimants have the same information about asset value, characteristics of bankruptcy procedure and judge behaviour. In spite of bargaining being costly, we show that our perfect and complete information setting can generate more than one round of renegotiations. This is because claimholders are unsure about the judge behaviour, and assign probabilities about her intervention in the negotiation process. In contrast to Giammarino (1989) who argues that informational asymmetries increase the number

\footnotetext{
${ }^{1}$ This first plan is in the best interests of shareholders as we abstract from agency conflicts between claimants.

${ }^{2}$ Berkovitch, Israel and Zender (1998) show that judge interference in the procedure is a direct restriction on the bargaining game that prevents claimholders from acting too strategically.

${ }^{3}$ One exceptional case of asset stripping is the failure of Eastern Airlines documented by Weiss and Wruck (1998).
} 
of bargaining rounds and may require the intervention of the Court, we show that even homogenous information among claimholders can generate multiple round bargaining as soon as the judge behavior is perceived as uncertain.

\subsection{The firm}

We consider a firm financed by two classes of debt with different priorities, paying a constant and continuous coupon $c$ to the creditors, and a constant dividend to the equityholders, until default. We denote by $V_{t}$ the the value of the firm's assets at time $t$ and assume that $V_{t}$, which plays the role of a state variable, is instantly observable by all players. The default event, at $t=0$, starts the negotiation process under Chapter 11 . We assume that coupon and dividend payments are suspended during Chapter 11 negotiation, and resume if and once the firm emerges from the process as a reorganized entity, at date $t^{*}$. The firm's assets value then follows a regime-switching log-normal process under the risk neutral measure:

$$
d V_{t}= \begin{cases}r V_{t} d t+\sigma V_{t} d Z_{t} & \text { if } 0 \leq t<t^{*} \\ (r-\delta) V_{t} d t+\sigma V_{t} d Z_{t} & \text { if } t^{*} \leq t<T\end{cases}
$$

where $r$ denotes the risk-free rate, $\delta$ the dividend payout rate, $\sigma$ the volatility of the assets, $Z_{t}$ is a $Q-$ Brownian motion and $T$ is a stopping time representing the eventually reorganized firm default event date.

\subsection{The players}

The negotiation process under Chapter 11 involves all the claimants of the firm, as well as the bankruptcy judge. The creditors and equityholders are strategic participants, having a stake in the firm, while the bankruptcy judge is a non-strategic player.

We assume the interests of the equityholders are represented by the same board of directors as prior to filing and identify it with a single player, denoted Player $e$. The creditors are divided into two classes of substantially similar claims, labeled senior and junior (subordinated). As provided in the Code, the bankruptcy judge appoints a committee to represent the interests of creditors in each class during the reorganization. We identify 
single players, denoted respectively by $s$ and $j$, with the negotiators representing the interest of senior and junior creditors. During the negotiation process, strategic players $e, s$ and $j$ take their decisions independently, by taking into account their best individual interest.

Empirical evidence suggests that the bankruptcy judge, while having no personal stake in the negotiation, does influence the negotiation by controlling key parameters of the process. Here, we let the judge decide on the maximum number of negotiation rounds, denoted $K$, and allow her to intervene and stop the process at any round if an agreement is not reached among the strategic players. The probability of the judge's intervention at round $k$, denoted by $q_{k}$, reflects the impatience of the judge, and can, for instance, increase with the number of bargaining rounds and/or the length of the negotiation process.

Conditional on intervening, we further assume that the judge can either cramdown a reorganization plan, or convert Chapter 11 negotiation into Chapter 7 liquidation. ${ }^{4}$ In the event of a cramdown, the judge can decide to impose the last proposed plan, or any other reorganization plan she finds "fair and equitable". What the judge will decide is not known with certainty, and we denote by $z$ the probability that the judge imposes her own plan. A parameter, denoted $\beta$, describes the judge's attitude towards the claimants, that is, the relative weight allocated to them in her own reorganization plan. The judge's behavior is thus characterized by the parameters $K, q_{k}, z$, and $\beta$, which we assume known by all the claimants at the beginning of the negotiation process.

\subsection{Bankruptcy costs}

Bankruptcy costs are divided into two categories: financial distress costs are borne during the negotiation process, while liquidation costs reduce the value recovered from the assets in the case of a liquidation. Bankruptcy costs play an important role, making a prompt negotiated outcome interesting for all parties.

\footnotetext{
${ }^{4}$ To liquidate the firm, the bankruptcy judge can invoke one of the causes described in section 1112(b)(4) of the Bankruptcy Code. For example, showing that there is substantial or continuing loss to the estate and the absence of a reasonable likelihood of rehabilitation. Other causes can include some negotiation technicalities.
} 
We model financial distress costs that are proportional both to the value of the assets at the beginning of Chapter 11 negotiation, and to the length of the negotiation process, capturing elements of direct (legal fees) as well as indirect (productivity loss) costs. For simplicity, we assume that all bargaining rounds are of equal length $d$. Accordingly, an amount $\theta V_{0} d$ is due (in priority) at the end of each bargaining round, thus reducing the total value of the shares of the claimants in the reorganized firm. In order to keep track of the cumulated value of the financial distress costs, capitalized at rate $r$, at the end of negotiation round $k$, define

$$
\begin{aligned}
C_{k} & =\sum_{j=0}^{k-1}\left(1+e^{r d j}\right) \theta V_{0} d \\
& =\frac{1-e^{r d k}}{1-e^{r d}} \theta V_{0} d .
\end{aligned}
$$

On the other hand, liquidation costs are assumed to be proportional to the firm's remaining asset value, net of financial distress costs. The proportion of the ex-financial distress costs asset value recovered in the case of a liquidation is denoted by $1-\alpha$.

\subsection{Chapter 11 outcomes}

According to the provisions of the Code, each negotiation round consists in the proposal of a reorganization plan by one of the player to the other claimants, who then vote to accept or reject it. Thus, at each negotiation round, a plan is submitted by one of the players, labeled Leader, to the two other players, labeled Follower 1 and Follower 2. We consider three possible outcomes, depending on the followers' reaction to the leader's proposition.

In the first case, the firm is reorganized and emerges as a new entity. This new firm is shared between the claimants either according to the plan proposed by the leader at that round (if the followers agreed to it, or if the judge imposed it), or according to a plan decided by the judge. In the second case, the firm is liquidated. This happens if the judge decides to stop the negotiation process when the plan proposed by the leader is unanimously rejected by the two followers. Finally, in the third case, nothing is resolved and the process moves to the next negotiation round, where another player is selected to propose a new 
reorganization plan. This happens if the judge does not interfere in the bargaining process when the followers do not accept the leader's proposition. However, since financial distress costs are borne continuously during the negotiation process, whenever the firm's assets value is no longer sufficient to cover the cumulated financial distress costs, then the reorganization process stops and the firm is immediately liquidated under Chapter 7 of the Code, leaving nothing to the claimants.

\section{Solving the negotiation game}

In this section, we solve for the equilibrium strategies of the three strategic players, and obtain, for each player, the expected value of the outcome of the negotiation game, at the moment the default event is triggered.

\subsection{Time sequence of events}

Our model spans the life of the firm, over an infinite horizon, starting from $t=0$ when a default event triggers the Chapter 11 negotiation process. If the process results in a reorganization, at date $t^{*}$, the reorganized firm continues operating until a second default event occurs at date $T$.

We assume that the financial distress costs are covered by the firm's asset during the negotiation process. The firm stops operating, with a null recovery value, if at any time during the negotiation the value of the assets vanishes.

At $t=0$, coupon and dividend payments are suspended. The equityholder then has $d$ units of time to prepare a first reorganization plan to be submitted to the creditors.

At $t=d$, provided $V_{d}>C_{1}$, the first plan is proposed. If both creditors approve the plan, or if the judge intervenes with a cram-down, a new reorganized firm emerges; this firm distributes dividends and new reorganized coupons, and continues its operations until $T$. If the judge intervenes and imposes liquidation, the firm is liquidated according to the Absolute Priority Rule and the process terminates. Otherwise, the negotiation process 
continues: the junior creditor has $d$ units of time to prepare a second reorganization plan to be submitted to the two other claimants, namely the equityholder and the senior creditor.

At $t=2 d$, provided $V_{2 d}>C_{2}$, the second plan is proposed. Again, the firm may emerge if both players approve the plan, or if the judge cramdowns a plan, or may be liquidated if the judge so decides. Otherwise, the senior creditor has $d$ units of time to prepare a third reorganization plan to be submitted to the two other claimants.

At $t=3 d$, provided $V_{3 d}>C_{3}$, the third plan is proposed, with the three same possible outcomes. If the process continues, the claimants alternate in proposing reorganization plans following the same sequence, until either the firm is reorganized or liquidated.

For simplicity and tractability reasons, we assume that any further financial distress after the firm emerges from Chapter 11 leads to the liquidation of the firm.

\subsection{Outcome values}

In our setting, the players strategies and the resulting Chapter 11 outcomes depend on the observed level of the assets value, which defines the state of the system, and on the initial debt contract, represented here by the contractual coupons, which are given parameters. We denote the contractual coupons by $c^{0}=c_{s}^{0}+c_{j}^{0}$, where $c_{s}^{0}$ is the senior debt coupon and $c_{j}^{0}$ is the subordinated debt coupon. In the following subsections, we compute the value of what each claimant receives according to the outcome of the negotiation process, at discrete times $t=k d$ corresponding to the end of the $k$ th negotiation round. To keep track of the value of assets net of financial distress costs at date $t=k d$ when $v=V_{k d}$, we define the auxiliary variable $w_{k} \equiv v-C_{k}$.

\subsubsection{Liquidation}

If the firm is liquidated after $k$ negotiation rounds at time $t=k d$, the assets of the firm, net of the financial distress costs, are disposed of at a proportional liquidation $\operatorname{costs} \alpha$. The liquidation value of the firm thus depends on the asset value $v=V_{k d}$ and on the cumulated 
financial distress costs at the end of round $k$, and is given by:

$$
\omega_{F}^{L}(v, k)=\max \left[(1-\alpha) w_{k}, 0\right]
$$

If $w_{k} \leq 0$, then nothing is left to be shared among the claimants and $\omega_{F}^{L}(v, k)=0$. However, if $w_{k}>0$, then the senior, junior and equityholders liquidation payoffs, according to Absolute Priority Rule, depend on the contractual coupons $c_{s}^{0}$ and $c_{j}^{0}$, and are given respectively by

$$
\begin{gathered}
\omega_{s}^{L}(v, k)=\min \left[\omega_{F}^{L}(v, k), \frac{c_{s}^{0}}{r}\right], \\
\omega_{j}^{L}(v, k)=\min \left[\max \left[\omega_{F}^{L}(v, k)-\frac{c_{s}^{0}}{r}, 0\right], \frac{c_{j}^{0}}{r}\right],
\end{gathered}
$$

and

$$
\omega_{e}^{L}(v, k)=\max \left[\omega_{F}^{L}(v, k)-\frac{c^{0}}{r} ; 0\right] .
$$

We denote by $\omega^{L}(v, k)=\left(\omega_{s}^{L}(\cdot), \omega_{j}^{L}(\cdot), \omega_{e}^{L}(\cdot)\right)$ the vector of liquidation values at assets value $v$ and negotiation round $k$.

\subsubsection{Emergence values}

If the firm emerges from financial distress after $k$ negotiation rounds at time $t=k d$ and asset value $v=V_{t}-C_{k}>0$, then the reorganized firm continues its operations by distributing new coupons $c_{s}$ and $c_{j}$ to the senior and junior creditors respectively, until further default at time $T$. Recall that we assume that further default leads to immediate liquidation. The value at $(v, k)$ of the reorganized firm depends on the reorganized coupon and on the value of the assets, net of financial distress costs, at the emergence from Chapter 11, and is given by:

$$
\mathbb{E}_{v t}\left[\int_{t}^{T}\left(\tau c+\delta V_{u}\right) e^{-r(u-t)} d u\right]+(1-\alpha) \mathbb{E}_{v t}\left[e^{-r(T-t)} B\right]
$$

where $\mathbb{E}_{v t}(\cdot)$ denotes the expectation $\mathbb{E}^{Q}\left(\cdot \mid t, V_{t}=v\right)$ under the risk-neutral measure $Q, \tau$ represents the tax rate, $c \equiv c_{s}+c_{j}$ is the total reorganized coupon, $\delta$ the payout rate, $r$ the risk-free interest rate, $\alpha$ the proportional liquidation costs and $B$ the final default barrier. 
Equivalently, the value of the firm after emergence, which is the object of bargaining between claimants, is given by:

$$
\omega_{F}^{R}(v, c, k)=w_{k}+\frac{\tau c}{r}\left(1-\left(\frac{B}{w_{k}}\right)^{\frac{\lambda}{1-\lambda}}\right)-\alpha B\left(\frac{B}{w_{k}}\right)^{\frac{\lambda}{1-\lambda}}
$$

where $\lambda=\frac{\gamma+\eta}{\gamma+\eta+\sigma}, \gamma=\frac{\left(r-\delta-\frac{\sigma^{2}}{2}\right)}{\sigma}$ and $\eta=\sqrt{2 r+\gamma^{2}}$. The first term in (8) is the value of the assets at the emergence time, the second term is the present value of tax benefits of the operating firm, and the third term is the present value of liquidation costs.

Denote the liquidation values for each claimant at the final default barrier $B$ when the reorganized coupon pair is $\bar{c} \equiv\left(c_{s}, c_{j}\right)$ by $\omega_{i}^{D}(B, \bar{c}), i \in\{s, j, e\}$. Upon reorganization at $(v, k)$ with a new coupon $c=c_{s}+c_{j}$, the value for the three claimants (senior creditor, junior creditor and equityholder) is therefore given respectively, for $v>C_{k}$, by

$$
\omega_{i}^{R}(v, \bar{c}, k)=\frac{c_{i}}{r}\left(1-\left(\frac{B}{w_{k}}\right)^{\frac{\lambda}{1-\lambda}}\right)+\omega_{i}^{D}(B, \bar{c})\left(\frac{B}{w_{k}}\right)^{\frac{\lambda}{1-\lambda}}, i \in\{s, j\}
$$

and

$$
\begin{aligned}
& \omega_{e}^{R}(v, \bar{c}, k) \\
= & \omega_{F}^{R}(v, c, k)-\left(\omega_{s}^{R}(v, \bar{c}, k)+\omega_{j}^{R}(v, \bar{c}, k)\right) \\
= & w_{k}-\frac{(1-\tau) c}{r}\left(1-\left(\frac{B}{w_{k}}\right)^{\frac{\lambda}{1-\lambda}}\right)-B\left(\frac{B}{w_{k}}\right)^{\frac{\lambda}{1-\lambda}}+\omega_{e}^{D}(B, \bar{c}) .
\end{aligned}
$$

Following Leland (1994), we assume that default is decided by equityholders, and that the liquidation barrier $B$ is determined so as to maximize equity value, given the limited liability of equityholders. The optimal liquidation barrier for equityholders is then

$$
B=\frac{(1-\tau) \lambda}{r} c .
$$

Notice that the reorganized coupon $c$ has a direct impact on the liquidation barrier. Using the expression of the default barrier in (11) and rearranging (8), the total value of the firm at $v, k$ when the reorganized coupon is $c$ for $v>C_{k}$ is given by:

$$
\begin{aligned}
& \omega_{F}^{R}(v, c, k) \\
= & \frac{w_{k}}{\lambda}\left(\lambda+\tau \frac{\lambda c}{r w_{k}}-\left(\frac{\tau}{1-\tau}+\lambda \alpha\right)\left(\frac{(1-\tau) \lambda c}{r w_{k}}\right)^{\frac{1}{1-\lambda}}\right)
\end{aligned}
$$


As developed by Leland (1994), the liquidation leaves the creditors with value $(1-\alpha) B$ and the equityholders with nothing. Rearranging (9), the total value of debt for $v>C_{k}$ is given by

$$
\begin{aligned}
& \omega_{s}^{R}(v, \bar{c}, k)+\omega_{j}^{R}(v, \bar{c}, k) \\
= & \frac{w_{k}}{\lambda}\left(\frac{\lambda c}{r w_{k}}-\left(\frac{1}{1-\tau}-\lambda(1-\alpha)\right)\left(\frac{(1-\tau) \lambda c}{r w_{k}}\right)^{\frac{1}{1-\lambda}}\right),
\end{aligned}
$$

while the value of equity for $v>C_{k}$ is

$$
\begin{aligned}
& \omega_{e}^{R}(v, c, k) \\
= & \frac{w_{k}}{\lambda}\left(\lambda-\frac{(1-\tau) \lambda c}{r w_{k}}+(1-\lambda)\left(\frac{(1-\tau) \lambda c}{r w_{k}}\right)^{\frac{1}{1-\lambda}}\right) .
\end{aligned}
$$

Notice that, at a given time $k d$ and asset value $v$, both the value of the reorganized firm and of the reorganized debt are concave in $c$, while the value of equity is decreasing in $c$.

We denote by $\omega^{R}(v, \bar{c}, k)=\left(\omega_{s}^{R}(\cdot), \omega_{j}^{R}(\cdot), \omega_{e}^{R}(\cdot)\right)$ the vector of reorganization values at asset value $v$, negotiation round $k$ and when the reorganized coupon pair is $\bar{c}$.

\subsubsection{The role of the judge}

A reorganized firm may emerge from financial distress after $k$ negotiation rounds at time $t=k d$ and asset value $v=V_{t}$ under the bankruptcy judge's plan. We suppose that the judge's plan is, as stipulated in the Code, fair and equitable; in that respect, we assume that the judge's plan gives to each player at least his liquidation payoff, thus ruling out Absolute Priority Rule violation, and shares the residual value among the claimants according to some sharing vector, denoted by $\beta=\left(\beta_{s}, \beta_{j}, \beta_{e}\right)$, satisfying:

$$
0 \leq \beta_{i} \leq 1, \quad i \in\{s, j, e\}
$$

and

$$
\sum_{i \in\{s, j, e\}} \beta_{i}=1
$$


Therefore, a reorganized coupon pair proposed by the bankruptcy judge, denoted $c^{\beta}$, is such that the each claimant's payoff satisfies

$$
\omega_{i}^{R}\left(v, c^{\beta}, k\right)=\beta_{i} \underbrace{\left(\omega_{F}^{R}\left(v, c^{\beta}, k\right)-\omega_{F}^{L}(v, k)\right)}_{\text {Residual value }}+\omega_{i}^{L}(v, k), \quad i \in\{s, j, e\}
$$

where $\omega_{F}^{R}\left(v, c^{\beta}, k\right)$ is the total firm value defined in (12) and the liquidation payoffs $\omega_{i}^{L}(v, k)$ are defined in $(4)-(6)$ for $i \in\{s, j, e\}$. For a given $(v, k)$, the reorganized coupon pair satisfying (15) is denoted by $c^{\beta}$ to simplify notation - but is a function of $(v, k)$ (see Appendix A). The sharing vector $\beta$ defines the proportion of the "benefits of reorganization" that each player gets from the judge's plan. This can be assimilated to the solution of a Nash bargaining game, where $\beta$ would then represent the vector of the claimant's bargaining powers, the residual value corresponding to the benefit of cooperation between the claimants, and where the liquidation payoffs represent the non-cooperation threat.

\subsubsection{Continuation values}

If the firm is neither reorganized, nor liquidated after $k$ negotiation rounds, then we define continuation values at time $t=k d$ and state variable value $v=V_{t}$, which are the expected values of the players future payoffs, taking into account the dynamics of the firm's asset value.

Denote $\omega^{*}(v, k)=\left(\omega_{s}^{*}(\cdot), \omega_{j}^{*}(\cdot), \omega_{e}^{*}(\cdot)\right)$ the vector of equilibrium outcomes of negotiation round $k$ when the firms' assets value $V_{k d}=v, k \in[1, K]$, that is, for a claimant $i \in\{s, j, e\}:$

$$
\omega_{i}^{*}(v, k)=\left\{\begin{array}{ll}
0 & \text { if } v \leq C_{k} \\
\omega_{i}^{L}(v, k) & \text { if the firm is liquidated } \\
\omega_{i}^{R}(v, \bar{c}, k) & \text { if the firm is reorganized with } \bar{c} \\
\omega_{i}^{C}(v, k) & \text { otherwise }
\end{array}\right\} \text { if } v>C_{k}
$$

where the continuation payoff $\omega_{i}^{C}(v, k)$ for each player is defined as the expected value of the outcome at the next bargaining round, and continuation is not allowed when the game 
reaches the end of the negotiation process, such that, for $i \in\{s, j, e\}$,

$$
\omega_{i}^{C}(v, k)= \begin{cases}e^{-r d} \mathbb{E}_{v t}\left[\omega^{*}\left(V_{(k+1) d}, k+1\right)\right] & \text { for } k=0, \ldots, K-1 \\ 0 & \text { for } k=K .\end{cases}
$$

We denote by $\omega^{C}(v, k)=\left(\omega_{s}^{C}(\cdot), \omega_{j}^{C}(v, k), \omega_{e}^{C}(v, k)\right)$ the vector of continuation outcomes at $(v, k)$ and $\omega_{F}^{C}(v, k)=\omega_{s}^{C}(v, k)+\omega_{j}^{C}(v, k)+\omega_{e}^{C}(v, k)$ the continuation value of the firm at $(v, k), k \in[0, K]$.

\subsection{Negotiation round game}

Table 1 depicts the normal form representation of the game at a given round $k$, between the claimant who proposes a reorganization plan, labelled 0 for "Leader", and the other two claimants, labelled 1 and 2 for "Follower 1" and "Follower 2", who vote on it. Notice that we use numerical labels when the claimants are referred by their role as players in the negotiation process, $i=\{0,1,2\}$, and literary labels when they are identified by their role as stakeholders, $i=\{s, j, e\}$.

The outcome of a given negotiation round depends on the pair of binary decisions made by Followers 1 and 2, on the plan proposed by the leader, on the continuation values, and on the judge's behavior. We use a Stackelberg/Nash equilibrium solution concept to solve this three-player game, where the outcomes are vectors in $\mathcal{R}^{3}$. Thus, when the leader proposes his reorganization plan, he takes into account the equilibrium reactions of the two followers, where neither player has a unilateral incentive to change his strategy.

Notice that a reorganization plan is completely defined by a proposal $\bar{c}=\left(c_{s}, c_{j}\right)$ for the reorganized coupon, which is sufficient to compute the share of each player in the reorganized firm, according to (9) and (14).

Consider each possible pair of binary decisions by the followers, denoted $D=\left(D_{1}, D_{2}\right)$, where $D_{i} \in\{A, R\}$ is the decision of Follower $i, A$ stands for "Accepting the leader's plan" and $R$ stands for "Rejecting the leader's plan". For each decision pair, the best proposal of the leader, taking into account the reactions of the followers to his proposal, is a plan 
$\bar{c}=\left(c_{s}, c_{j}\right)$ solving at a given $t=k d, v=V_{t}$, an optimization problem of the form:

$$
\begin{array}{ll} 
& \max _{\bar{c}} O_{0}^{D}(v, k) \\
\text { s.t. } & O_{i}^{D}(v, k) \lesseqgtr b_{i}, i \in\{1,2\},
\end{array}
$$

where $O_{i}^{D}$ represents the expected value of the outcome of the negotiation round for player $i$ if the followers choose decision pair $D$, and $b_{i}$ represents what Follower $i$ can achieve by unilaterally deviating from his decision. The four possible combinations of decisions taken by the followers thus define four different optimization problems, and their solutions specify the best plan that the Leader can propose for each of these four possible situations. Notice that the precise formulation of these four optimization problems depends on the identity, as stakeholders, of the leader and followers.

For a given $(v, k), v>C_{k}$, define the auxiliary variable

$$
y=\frac{B}{w_{k}}=\frac{\lambda(1-\tau)}{r w_{k}} c
$$

the "distance to default" at $w_{k}$. Notice that $y$ is proportional to $c$ at $(v, k)$, so that it uniquely defines the total coupon in any reorganization plan at $(v, k)$. Feasible values of $y$ are in the interval $[0,1]$. In all cases, that is, for all possible decision pairs and identity of the leader and followers, optimization problem (18)-(19) can be transformed by a simple change of variable into an equivalent problem of maximizing a concave function of $y$ over a closed interval, and solutions for all possible cases can be obtained analytically (see Appendix A). The solution of optimization problem (18)-(19) at $(v, k)$ when the decision pair of the followers is $D$ yields the best plan, denoted $c^{D}(v, k)$, and the corresponding optimal expected value of the leader's outcome, denoted $\omega_{0}^{D}(v, k)$.

The equilibrium strategy vector for a given negotiation round when the asset value is $v$, denoted $\chi(v, k)=\left(\chi_{i}(\cdot)\right), i \in\{0,1,2\}$, is obtained by comparing the leader's best outcome corresponding to each of the four possible decision pairs. The leader's equilibrium strategy is the one that maximizes his share, so that the equilibrium outcome vector and strategies 
at $t=k d, v=V_{t}$ are given by:

$$
\begin{aligned}
D^{*}(v, k) & =\arg \max _{D}\left\{\omega_{0}^{D}(v, k)\right\} \\
\chi_{0}(v, k) & =c^{D^{*}(v, k)}(v, k) \\
\chi_{i}(v, k) & =D_{i}^{*}(v, k), i \in\{1,2\} \\
\omega_{i}^{*}(v, k) & =\omega_{i}^{D^{*}(v, k)}(v, k), i \in\{0,1,2\} .
\end{aligned}
$$

\subsection{Equilibrium solution}

At $t=k d, k=0, \ldots, K$, and asset value $v=V_{t}$, denote $\omega_{i}(v, k)$ the expected value, for claimant $i$, of what he will ultimately recover from the Chapter 11 process, and $\omega_{F}(v, k)$ the total value of the firm. These value functions are defined recursively by the following dynamic program

$$
\begin{aligned}
\omega_{i}(v, k) & =\omega_{i}^{*}(v, k), k=1, \ldots K \\
\omega_{i}(v, 0) & =e^{-r d} \mathbb{E}_{v 0}\left[\omega_{i}\left(V_{d}, 1\right)\right] \\
\omega_{F}(v, k) & =\sum_{i \in\{s, j, e\}} \omega_{i}(v, k), k=0, \ldots K,
\end{aligned}
$$

where $\omega_{i}^{*}(v, k)$ is defined by (16)-(17), and where the equilibrium outcomes are determined by solving the negotiation game at each round. At the entry in Chapter 11, the share of the firm expected by each claimant and the value of the firm are given by $\omega_{i}\left(V_{0}, 0\right)$ and $\omega_{F}\left(V_{0}, 0\right)$.

Starting from the last negotiation round, the equilibrium outcome vector is obtained by backward induction as a function of $k$ and $v=V_{k d}$. Notice that the equilibrium outcome vector at a given $k$ cannot be obtained in closed-form as a function of $v$, and we use a numerical algorithm to compute, at a given negotiation round, the outcomes of claimants on a grid of discretized asset values. Each claimant's outcome function at a given $k$ is then approximated by a piecewise linear interpolation function, which is then used in (17) to obtain the continuation values. Details about the interpolation function and the backward recursion algorithm are given in Appendix B. 


\section{Numerical implementation}

This section presents the model calibration. A sample of firms filing Chapter 11 is specifically constructed to estimate firm-specific parameters like asset returns expectation and volatility, coupon rate, and share of senior debt. Other parameters including costs and duration of the bankruptcy procedure, are set according to recent empirical studies on Chapter 11.

\subsection{The data}

Our sample consists in U.S. public firms that filed for Chapter 11 over the period 1997 to 2007. Filings records are obtained from BankruptcyData (www.bankruptcydata.com), a division of New Generation Research, Inc. Our initial sample contains 1,811 filings that led to either liquidation, reorganization or merger. We first restricted the data to large companies with total asset value of more than $\$ 1$ billion. This first filter led to 183 filings. Second, we excluded financial, insurance, real estate and public administration firms since they have a different treatment under Chapter 11. The second filter led to 156 filings.

All the firm-level data are obtained from Compustat and are measured as of the last two years before the default date. Because of our reliance on Compustat for firm-specific data, we excluded 25 filings not covered by this database. Among the filings that were left, three firms filed for Chapter 11 twice during our sample period. ${ }^{5}$ Our final sample consists of 128 firms and 131 Chapter 11 cases.

Table 2 provides information on the filing dates as well as the industry distribution. Not surprisingly and as shown by Panel A, the majority of firms in our sample filed for Chapter 11 during the 2001-2002 recession.

\footnotetext{
${ }^{5}$ Montgomery Wald Holding filed for Chapter 11 in 07/07/1997 and then in 12/28/2000. McLeod USA INC defaulted in 1/30/2002, emerged and then defaulted again in 2005. U.S. Airways was reported as Passenger Airline that entered into Chap 11 in 08/11/2002 and then as Holding company for Passengers Airlines that defaulted in 09/12/2004. For each of these companies, we keep both default events as observations in our sample.
} 


\subsection{Model calibration}

The average 10-year Constant Maturity Treasury (CMT) over the 1997-2007 period is $3.83 \%$. Consequently, we set $r=4 \%$. Apart from the risk-free rate, the parameters of our model can be classified into two categories: firm-specific parameters and bankruptcy-specific parameters. Table 3 summarizes the calibration results.

\subsubsection{Firm-specific parameters}

These parameters must characterize a typical firm initiating a Chapter 11 filing. We first compute the series of quarterly log-returns on assets for the 131 sample firms over the two years prior to their entry in Chapter 11. Median values for the expected return and volatility of assets returns are $1.41 \%$ and $34 \%$, respectively. Accordingly, we set $\mu=1.5 \%$ and $\sigma=35 \%$.

For each filing firm, the coupon rate (in percentage of asset value) is obtained by multiplying book leverage with the risk-free rate. Book leverage is calculated from the quarterly balance sheet on the eight quarters preceding Chapter 11 filing, that is, for firm $n$

$$
\text { Book leverage }_{n}=\frac{1}{8} \times \sum_{i=1}^{8}\left(\frac{\text { Total debt }_{n, i}}{\text { Total debt }_{n, i}+\text { Total equity }_{n, i}}\right)
$$

where total equity is approximated by

$$
\begin{aligned}
\text { Total equity }_{n, i}= & \text { Common equity }_{n, i}-\text { Purchase of common } \\
& \text { and preferred stocks }{ }_{n, i}+\text { Sale of common } \\
& \text { and preferred stocks } s_{n, i},
\end{aligned}
$$

and total debt is approximated by

$$
\text { Total } \text { debt }_{n, i}=\text { Long term } \text { debt }_{n, i}+\text { Debt in current liabilities }_{n, i} \text {. }
$$

Our coupon rate ( $c=10$ with $V=100)$ is the rounded value of the median coupon rate (0.1077). 
The share of senior debt is computed from the annual balance sheet over the two years preceding Chapter 11 filing as ${ }^{6}$

$$
\xi_{n}=1-\frac{1}{2} \times \sum_{i=1}^{2}\left(\frac{\text { Debt subordinated }}{n, i}\right) .
$$

The median of all $\xi_{n}$ is $81.13 \%$, so we set $\xi=80 \%$.

For firms emerging from Chapter 11, we set the net tax advantage of debt equal to $30 \%$, in line with the estimates of Graham and Mills (2008), and the payout rate equal to $2 \%$, in line with the estimates of Ericsson and Reneby (2005).

\subsubsection{Bankruptcy-specific parameters}

In our model, the bankruptcy procedure is completely characterized by the maximum number of negotiation rounds, the duration of each bargaining round, the probabilities of the judge's interference and cramdown, and the vector $\beta$ reflecting the judge's own reorganization plan. We also need to specify the costs associated to the procedure.

Carapeto (2005) shows that on a sample of 144 Chapter 11 firms that reorganized successfully and had more than one plan over the period 1986-1997, the average number of reorganization plans is 3.2. Moreover, she shows that about two-thirds of Chapter 11 firms require more than one plan before an agreement can be attained. Consequently, we assume a total number of negotiation rounds $K=3$, thus allowing each claimant to present their reorganization plan. Furthermore, the recently amended paragraph 1121 of the Bankruptcy Code states that the 180-day period for obtaining plan approval may not be extended beyond 20 months. We therefore set bargaining rounds of constant length $d=2$ years. These parameters lead to a maximum procedure of 6 years, which is roughly consistent with empirical studies on Chapter 11 durations. For instance, Bris, Welsch and Zhu (2006), Denis and Rodgers (2007), and Kalay, Singhal and Tashjian (2007) document durations of Chapter 11 ranging from less than one year to more than 8 years.

As far as the judge behavior is concerned, we assume that her impatience is constant

\footnotetext{
${ }^{6}$ The quarterly amount of subordinated debt is not reported by Compustat.
} 
during the reorganization process, ${ }^{7}$ and we assume there is $75 \%$ chance (i.e. $q_{k}=\frac{3}{4}$ for $1 \leq k \leq K)$ that she intervenes. ${ }^{8}$ We further assume the judge is equally likely to impose the last proposed plan or her own. Accordingly, we set $z=0.5$. Finally, to reinforce the fairness and equity characteristics of the judge's plan, it is reasonable to assume that the residual value is equally distributed among the claimants, leading to a sharing vector $\beta=\left(\frac{1}{3}, \frac{1}{3}, \frac{1}{3}\right)$.

In our model, bankruptcy costs are broken down into two components: liquidation and financial distress costs. Liquidation costs are proportional to the current asset value by a factor $\alpha$. Financial distress costs are assumed proportional to the length of the process and are characterized by a factor $\theta$.

The empirical literature offers different estimation methods and a wide range of values for bankruptcy costs. We use the estimates provided by Bris et al. (2006) as inputs to our model. Our choice is motivated by the following reasons. First, these estimates are based on the largest Chapter 11 sample in the literature. ${ }^{9}$ Second, their sample provides estimates of both the liquidation and financial distress costs. Third, their sample period, which ranges from 1995 to 2001, is close to ours. In addition, they estimate direct financial distress costs as a proportion of the assets value at the entry at Chapter 11. Therefore, we use liquidation costs of $2 \%$. Bris et al. (2006) find average direct financial distress costs equal to $9.5 \%$. Not

\footnotetext{
${ }^{7}$ The assumption of constant interference probability results from two opposite considerations. On one hand, Baird and Morrison (2001) point out that the judge holds the option to determine the renegotiation outcome and, as predicted by real options theory, is better off waiting for the arrival of new information (i.e. the judge becomes more patient with time). On the other hand, welfare concerns induce the judge to accelerate the costly procedure (i.e. the judge becomes less patient with time).

${ }^{8}$ Although we could not find direct evidence on judge intervention frequency, Evans (2003) documents frequent judicial discretionary actions in Chapter 11. For instance, among the 290 cases in her sample, the judge decided to alter the exclusivity period (i.e. the length of the first round) in 120 cases. She also finds significant differences in discretionary actions as well as bankruptcy outcomes across judges - reinforcing the idea that judge behaviour is not entirely predictable by claimholders.

${ }^{9}$ Altman (1984) uses a sample of 19 cases, Weiss (1990) uses 37 cases, Betker (1997) 75 cases, Lubben (2000) 22 cases, and LoPucki and Doherty (2004) 48 cases, while Bris et al. (2006) use a sample of 300 large filings.
} 
much is reported about indirect financial distress costs, but if we assume comparable order of magnitude, the total (direct and indirect) financial distress costs amount to $20 \%$ of the assets value at the entry in Chapter 11 per year.

\section{Analysis of results}

We start by reporting the main output of the model, namely the different plans proposed at each round as a function of asset value. This allows us to identify the possible equilibria and their corresponding range for asset value. Next, we infer the probabilities associated to each outcome, the average time spent in Chapter 11 as well as the frequency of violations from the Absolute Priority Rule (APR) - three quantities that we can relate to empirical data.

\subsection{Proposed plans}

Figure 1 depicts the plans proposed by the different classes of claimholders during the three rounds. These plans are summarized by the triplet of firm value fractions that are offered to each class of claimants.

For each round, there is a critical threshold for asset value below which the firm is liquidated. This threshold corresponds to the accumulated coupon payments and costs of financial distress, and therefore increases with the next round. Above this threshold, a reorganization plan is actually proposed.

Figure 1a shows the plans proposed by shareholders during the first round. For a sufficiently high level of asset value (around 62 in our base case), shareholders have no interest in making concessions with creditors, as they expect the firm to be wealthy enough to obtain better terms in the future. That is why they voluntarily offer a plan leaving nothing to senior creditors and a minimal share to junior creditors (to obtain their vote and avoid liquidation). Shareholders expect this plan to be either rejected - which will lead negotiations to the next round - or to be crammed down by the judge, giving them either "the fair and equitable" share or an extremely favorable outcome to them. 
As asset value goes lower, the likelihood of liquidation increases and induces shareholders to make concessions. As a matter of fact, they offer a plan that is accepted by both creditors when asset value lies within 48 and 62 .

But if asset value gets very close to the liquidation threshold (between 40 and 48 in our base case), shareholders' value becomes so small that they have an incentive to offer the plan that, again, shares nothing with senior creditors, and gives the smallest possible share to junior creditors. This "desperate" plan is motivated by the fact that, in expectation, shareholders are better off gambling on the judge intervention as they have almost nothing left to lose.

A similar logic applies to the second round. Figure $1 \mathrm{~b}$ shows that, when asset value is high enough, senior creditors will grant themselves almost all of firm value, leaving just a small fraction to shareholders to get their vote. Shareholders' acceptance is cheaper to buy since they are last in priority. Again, worst case for senior creditors is that the plan is rejected and negotiations move on to the third round. At best, the judge may cram down this plan that is extremely favorable to them.

For a wide set of intermediate values of asset (between 100 and 300 in our base case), senior creditors are better off reaching the unanimous consent, and the proposed shares reflect the relative priority of the three claimants.

As asset value gets very close to the liquidation threshold, senior creditors behave in a similar fashion as shareholders in the first round, as they offer again a "desperate" plan granting a minimal fraction to shareholders.

The logic is simplified when it comes to the third round since it is the last round. Junior creditors, who are now the leader, know they cannot expect negotiations to continue. But since they are last in priority, they find no benefit in making concessions. Hence the only plan they propose is the minimal fraction that warrants shareholders acceptance and the rest of firm value to them (see Figure 1c). Clearly, this plan can only be adopted but with judge cramdown. 


\subsection{Equilibrium probabilities}

We compute, for each round $k$, the probability that the geometric Brownian motion, initially starting at $v=V_{0}$ at the entry in Chapter 11, ends up in the domain of each equilibrium. These probabilities then need to be adjusted for judge intervention: In case of partial acceptance of the plan, there is a probability $q_{k}$ that the judge imposes a plan (her own with probability $z$ and the last proposed plan with probability $1-z$ ). This allows us to finally determine, for each round, the probabilities of liquidation, reorganization under the leader's plan and reorganization under the judge's plan (see Appendix C for details). Results are summarized in Tables 4 and 5.

Our calibrated base case yields a liquidation probability $(14.36 \%)$ that is in line with observed liquidation rates in Chapter 11 procedure. Table 6 Panel A surveys the liquidation rates reported by most recent empirical studies on Chapter 11 filings from public firms. These rates lie between $14 \%$ and $24 \%$, indicating a strong consensus between observed liquidation likelihood and our base case parameterization. Interestingly, the conditional liquidation probability of our model increases as one moves from one round to another, indicating the decay in reorganization possibilities as time passes.

There is approximately one third of chances that the judge will cramdown the "fair and equitable" plan, mostly after the first round. Unfortunately, we cannot relate this figure to any statistics about judge intervention. Our base case otherwise indicates that the most likely outcome is reorganization under shareholders' plan (42.04\% of probability). The probability of getting to the third round is small but this is caused by our stylized assumptions of three rounds of equal duration. As we will see in the next subsection, our calibration yields an overall Chapter 11 duration that is consistent with observations.

Equilibrium probabilities display great sensitivity to asset volatility. Consistent with intuition, very risky firms become more likely to be liquidated (probability increases to $24 \%$ ), while safer firms have greater chances of being reorganized under the Leader's plan - mostly shareholders' plan after the first round. Other sensitivities with firms-specific parameters are much smaller and in line with expectations (see Table 4). The firm will 
avoid liquidation and enjoy a reorganization plan as asset drift is higher and leverage is higher. This is in line with Denis and Rodgers (2007) who find a positive relation between the reorganization likelihood and the change in operating margin on one hand (although not significant), and the liability ratio prior to filing Chapter 11 on the other hand. We further note from Table 4 that liquidation probability slightly decreases as the junior creditor is less important. This is mostly explained by the fact that senior creditors will find it easier to have their plan accepted after the second round.

As far as bankruptcy-specific parameters are concerned, we note that when the judge can credibly signal her intention to impose her own plan (i.e. higher $z$ ), then claimholders have a stronger incentive to reach an agreement by themselves. As shown in Table 5, probability of liquidation as well as that of reorganization under the judge plan sharply decrease. The benefits of this incentive accrue to shareholders as they first propose a plan (compared to base case, the probability of reorganization under their plan goes from $52.42 \%$ to $70.50 \%$ as $z$ goes from 0.5 to 0.65$)$. As expected, liquidation probability decreases with costs of liquidation, but this effect is economically small. By contrast, costs of financial distress turn out to be a more important driver of outcome probabilities. A very costly procedure (say $\theta=30 \%$ ) reduces the scope for renegotiation and makes early liquidation more likely. The same effect is obtained by increasing the length of a round. As $d$ goes from 2 years (base case) to 3 years, liquidation probability increases (mostly in the first round) at the expense of all reorganization probabilities.

\subsection{Chapter 11 duration}

By weighting the length of each round with the corresponding probability of reorganization (either under Leader or judge plan), we can compute the model-implied duration of reorganization under Chapter 11 . With the base case, we obtain an average duration of

$$
365\left(2 \times \frac{42.04+31.89}{52.42+33.22}+4 \times \frac{10.26+1.2}{52.42+33.22}+6 \times \frac{0.12+0.12}{52.42+33.22}\right),
$$

that is, 832 days. This figure matches empirically reported Chapter 11 duration rather well. Table 6 Panel B reports the mean length of time spent in Chapter 11 according to empirical 
studies. This length of time lies within 708 and 915 days, with the exception of the study by Kalay et al. (2007) who find a significantly shorter Chapter 11 duration (447 days on average).

As expected, higher costs of financial distress induce claimholders to spend less time in renegotiations (average time to reorganization decreases to 794 days when $\theta=30 \%$ ). A similar remark holds when the judge is more prone to imposing her own plan (average time to reorganization decreases to 796 days when $z=0.65$ ). Other sensitivities are not economically meaningful, so we do not report them.

\subsection{APR violations}

From our model simulations, it is straightforward to infer the probability that the Absolute Priority will not be respected. Indeed, each claimholder votes in favor of the proposed plan provided the fraction of firm value they get is at least equal to the one obtained from the Absolute Priority Rule. As a consequence, deviations from the APR only occur when the following three conditions are met: (i) the plan is rejected, (ii) the judge intervenes, and (iii) she imposes the Leader's plan (and not the fair and equitable one).

The probability of deviation from the APR is therefore equal to the probability of reorganization under judge plan (as reported in Tables 4 and 5) multiplied by $1-z$. Thus, our base case parameters yield a probability of APR violations of $16.61 \%$. This figure is consistent with recent empirical estimates as reported from Table 6, Panel C.

\section{Conclusion}

In this paper, we have developed and solved a non-cooperative game approach to model renegotiations under the bankruptcy law. By doing so, we hope to contribute to the modelling of financial distress in the contingent claims literature, by opening "the black box" of Chapter 11 bargaining process. We show that rational claimholders can assess the likelihood of bankruptcy outcomes (liquidation or reorganization under different types of plans), using information about the firm and the legal procedure. Our approach uses a simple 
information structure and only relies on the perceived randomness of the judge's actions which is sufficient to generate multiple-round bargaining and multiple equilibria. A proper calibration of the model yields liquidation rate, Chapter 11 duration and percentage of deviations from the Absolute Priority Rule that are in line with statistics reported by empirical studies. The model also generates predictions as to how these observables are affected by changes in firm-specific or bankruptcy-specific parameters.

Admittedly, the modelling of negotiations under Chapter 11 could incorporate additional aspects that would possibly enrich the analysis, but also make the approach less tractable. For instance, informational asymmetries (i.e. shareholders and management having a more accurate knowledge of asset dynamics than creditors) could alter the equilibria of the game. In addition, conflicting interests between management and shareholders could modify the type of proposed plan - managers being primarily concerned with avoiding liquidation to keep their job. Li and Li (1999) argue however, that informational asymmetries and agency problems are less severe in legal bankruptcy than in private renegotiations, as claimholders are forced to disclose information.

Another direction for future research is to model more explicitly the role of the judge. Among the judge's primary goals, the literature on bankruptcy design (see e.g. Aghion, Hart and Moore, 1992) commonly cites: preserving the bonding role of debt (by enforcing the Absolute Priority Rule) and ensuring the bankruptcy procedure acts as an efficient "filter" for distressed firms (i.e. liquidating insolvent firms while reorganizing profitable ones). More personal career concerns (such as influence or prestige) could also be incorporated. This type of research direction is not trivial, as the judge 's objective function is, in essence, multi-dimensional.

\section{References}

[1] Aghion, P., Hart, O., and Moore, J., 1992. The Economics of Bankruptcy Reform. Journal of Law, Economics and Organization 8, 523-546. 
[2] Altman, E. I., 1984. A Further Empirical Investigation of the Bankruptcy Cost Question. Journal of Finance 39, 1067-1089.

[3] Anderson, R., and Sundaresan, S., 1996. The Design and Valuation of Debt Contracts. Review of Financial Studies 9, 37-68.

[4] Baird, D., and Morrison, E., 2001. Bankruptcy Decision Making. Journal of Law, Economics and Organization 17, 356-372.

[5] Berkovitch, E., Israel, R., and Zender, J., 1998. The Design of Bankruptcy Law: A Case for Management Bias in Bankruptcy Procedures. Journal of Financial and Quantitative Analysis 33, 441-64.

[6] Betker, B. L., 1997. The Administrative Costs of Debt Restructuring: Some Recent Evidence. Financial Management 26, 56-68.

[7] Bharath, S., Panchapegesan, V., and Werner, I., 2010. The Changing Nature of Chapter 11. Working Paper, University of Michigan.

[8] Bris, A., Welch, I., and Zhu, N., 2006. The Costs of Bankruptcy: Chapter 7 Liquidation versus Chapter 11 Reorganization. Journal of Finance 61,1253-1303.

[9] Broadie, M., Chernov, M., and Sundaresan, S., 2007. Optimal Debt and Equity Values in the Presence of Chapter 7 and Chapter 11. Journal of Finance 62, 1341-1377.

[10] Brown, D., 1989. Claimholder Incentive Conflicts in Reorganization: The Role of Bankruptcy Law. Review of Financial Studies 2, 109-123.

[11] Bruche, M., and Naqvi, H., 2010. A Structural Model of Debt Pricing with CreditorDetermined Liquidation. Journal of Economic Dynamics $\&$ Control 34, 951-967.

[12] Carapeto, M., 2005. Bankruptcy Bargaining with Outside Options and Strategic Delay. Journal of Corporate Finance 11, 736-746. 
[13] Chang, T., and Schoar, A., 2008. Judge Specific Differences in Chapter 11 and Firm Outcomes. Working Paper. MIT and NBER.

[14] Datta, S., and Iskandar-Datta, M. E., 1995. Reorganization and Financial Distress: An Empirical Investigation. Journal of Financial Research 18, 15-32.

[15] Davydenko, S. A., 2010. When Do Firms Default? A Study of the Default Boundary. Working Paper. University of Toronto.

[16] Denis, D. K., and Rodgers, K. J., 2007. Chapter 11: Duration, Outcome, and PostReorganization Performance. Journal of Financial and Quantitative Analysis 42, 101118.

[17] Eberhart, A. C., Moore, W. T., and Roenfeldt, R. L., 1990. Security Pricing and Deviations from the Absolute Priority Rule in Bankruptcy Proceedings. Journal of Finance 45, 1457-1469.

[18] Elayan, F., and Meyer, T., 2001. The Impact of Receiving Debtor-in-Possession Financing on the Probability of Successful Emergence and Time Spent Under Chapter 11 Bankruptcy. Journal of Business Finance and Accounting 28, 905-942.

[19] Ericsson, J., and Reneby, J., 2005. Estimating Structural Bond Pricing Models. Journal of Business 78, 707-735.

[20] Evans, J., 2003. The Effect of Discretionary Actions on Small Firms' Ability to Survive Chapter 11 Bankruptcy. Journal of Corporate Finance 9, 115-128.

[21] Fan, H., and Sundaresan, S., 2000. Debt Valuation, Renegotiation, and Optimal Dividend Policy. Review of Financial Studies 13, 1057-1099.

[22] François, P., and Morellec, E., 2004. Capital Structure and Asset Prices: Some Effects of Bankruptcy Procedures. Journal of Business 77, 387-411.

[23] Galai, D., Raviv, A., and Wiener, Z., 2007. Liquidation Triggers and the Valuation of Equity and Debt. Journal of Banking and Finance 31, 3604-3620. 
[24] Gertner, R., and Scharfstein, D., 1991. A Theory of Workouts and the Effects of Reorganization Law. Journal of Finance 46, 1189-1222.

[25] Giammarino, R. M., 1989. The Resolution of Financial Distress. Review of Financial Studies 2, 25-47.

[26] Gilson, S., John, K., and Lang, L., 1990. Troubled Debt Restructurings: An Empirical Study of Private Reorganization of Firms in Default. Journal of Financial Economics $27,315-353$.

[27] Graham, J., and Mills, L., 2008. Using Tax Return Data to Simulate Corporate Marginal Tax Rates. Journal of Accounting and Economics 46, 366-388.

[28] Hackbart, D., Hennessy, C., and Leland, H., 2007. Can the Tradeoff Theory Explain Debt Structure? Review of Financial Studies 20, 1389-428.

[29] Hege, U., and Mella-Barral, P., 2005. Repeated Dilution of Diffusely Held Debt. Journal of Business 78, 737-86.

[30] Helwege, J., 1999. How Long Do Junk Bonds Spend in Default? Journal of Finance $54,341-357$.

[31] Hotchkiss, E., and Mooradian, R., 2004. Post-Bankruptcy Performance: Evidence from 25 Years of Chapter 11. Working Paper. Boston College and Northeastern University.

[32] Kalay, A., Singhal, R., and Tashjian, E., 2007. Is Chapter 11 Costly? Journal of Financial Economics 84, 772-796.

[33] Li, D., and Li, S., 1999. An Agency Theory of the Bankruptcy Law. International Review of Economics 8 Finance 8, 1-24.

[34] Leland, H., 1994. Corporate Debt Value, Bond Covenants, and Optimal Capital Structure. Journal of Finance 49, 1213-1252. 
[35] LoPucki S. J., and Doherty, J. W., 2004. The Determinants of Professional Fees in Large Bankruptcy Reorganization Cases. Journal of Empirical Legal Studies 1, 111141.

[36] Lubben, S. J., 2000. The Direct Costs of Corporate Reorganization: An Empirical Examination of Professional Fees in Large Chapter 11 Cases. American Bankruptcy Law Journal 509, 508-552.

[37] Luther, K., 1998. An Artificial Neural Network Approach to Predicting the Outcome of Chapter 11 Bankruptcy. Journal of Business and Economic Studies 4, 57-73.

[38] Mella-Barral, P., 1999. The Dynamics of Default and Debt Reorganization. Review of Financial Studies 12, 535-578.

[39] Mella-Barral, P., and Perraudin, W., 1997. Strategic Debt Service. Journal of Finance $52,531-556$.

[40] Merton, R., 1974. On the Pricing of Corporate Debt: The Risk Structure of Interest Rates. Journal of Finance 29, 449-470.

[41] Moraux, F., 2002. Valuing Corporate Liabilities when the Default Threshold is not an Absorbing Barrier. Working Paper. University of Rennes I.

[42] Weiss, L., 1990. Bankruptcy Resolution: Direct Costs and Violation of Priority of Claims. Journal of Financial Economics 27, 285-314.

[43] Weiss, L., and Wruck, K. H., 1998. Information Problems, Conflicts of Interest, and Asset Stripping: Ch.11's Failure in the Case of Eastern Airlines. Journal of Financial Economics 48, 55-9.

[44] White, M., 1996. The Costs of Corporate Bankruptcy: A U.S.-European Comparison. In Bhandari J., Economic and Legal Perspectives, Cambridge UK: Cambridge University Press. 


\section{Appendix}

\section{Appendix A: Reorganization plans}

We first show that the judge's vector of weights $\beta$, along with sharing rule (15), defines a unique reorganization plan $c^{\beta}$ at $(v, k)$. We then derive the analytic solution to the optimization problem (18)-(19) for all combinations of decisions by the followers, and all possible identities of the leader.

Using the auxiliary variable $y$ defined in (20) in (8) and (10), the reorganization value of the firm, the equityholders, and of the creditors can be written as follows for $y \in[0,1]$ :

$$
\begin{gathered}
\omega_{F}^{R}(v, y, k)=\frac{w_{k}}{\lambda}\left(\lambda+\frac{\tau y}{1-\tau}-\left(\frac{\tau}{1-\tau}+\lambda \alpha\right) y^{\frac{1}{1-\lambda}}\right) \\
\omega_{e}^{R}(v, y, k)=\frac{w_{k}}{\lambda}\left(\lambda-y+(1-\lambda) y^{\frac{1}{1-\lambda}}\right) \\
\begin{aligned}
\omega_{d}^{R}(v, y, k) & \equiv \omega_{s}^{R}(v, y, k)+\omega_{j}^{R}(v, y, k) \\
& =\frac{w_{k}}{\lambda}\left(\frac{1}{1-\tau} y-\left(\frac{1}{1-\tau}-\lambda(1-\alpha)\right) y^{\frac{1}{1-\lambda}}\right) .
\end{aligned}
\end{gathered}
$$

\section{Bankruptcy judge's plan}

For a given asset value $v$ at negotiation round $k$, the reorganized coupon pair $c^{\beta}(v, k)$ satisfying (15) is obtained by solving

$$
\omega_{e}^{R}\left(v, c^{\beta}, k\right)-\beta_{e}\left(\omega_{F}^{R}\left(v, c^{\beta}, k\right)-(1-\alpha) w_{k}\right)=\omega_{e}^{L}(v, k) .
$$

Replacing $\omega_{F}^{R}$ and $\omega_{e}^{R}$ by their expression in (23)-(24) and rearranging yields

$$
\begin{aligned}
& y\left(1+\beta_{e} \frac{\tau}{1-\tau}\right)-y^{\frac{1}{1-\lambda}}\left(1-\lambda+\beta_{e}\left(\alpha \lambda+\frac{\tau}{1-\tau}\right)\right) \\
= & \lambda\left(1-\alpha \beta_{e}-\frac{\omega_{e}^{L}(v, k)}{w_{k}}\right)
\end{aligned}
$$


Differentiating the l.h.s. with respect to $y$, we obtain that the first derivative vanishes when $y^{\frac{\lambda}{1-\lambda}}=\frac{\left(1-\tau\left(1-\beta_{e}\right)\right)(1-\lambda)}{(1-\tau)(1-\lambda)+\beta_{e}(\tau+\alpha \lambda(1-\tau))} \in(0,1)$. Moreover, the second derivative is

$$
-\lambda y^{\frac{2 \lambda-1}{1-\lambda}} \frac{(1-\tau)(1-\lambda)+\beta_{e}(\tau+\alpha \lambda(1-\tau))}{(1-\lambda)^{2}(1-\tau)}<0 .
$$

We obtain that the l.h.s. is concave in $y$ and admits a maximum in $(0,1)$. Moreover its value is 0 at $y=0$, while it is $\lambda\left(1-\alpha \beta_{e}\right)>0$ at $y=1$. Therefore, there is a unique solution to $(26)$ corresponding to a value for $y$ in $[0,1]$ since $0 \leq \frac{\omega_{e}^{L}(v, k)}{w_{k}} \leq(1-\alpha)$, yielding

$$
0 \leq \lambda\left(1-\alpha \beta_{e}-\frac{\omega_{e}^{L}(v, k)}{w_{k}}\right) \leq \lambda\left(1-\alpha \beta_{e}\right)
$$

\section{Leader's optimal plan}

$D=(A, A)$ If both followers accept the plan, then the outcome vector is $\omega^{R}(v, \bar{c}, k)$. In that case, the leader's best proposal is the solution of

$$
\begin{aligned}
& \max _{\bar{c}} \omega_{0}^{R}(v, \bar{c}, k) \\
\text { s.t. } & \\
\omega_{i}^{R}(v, \bar{c}, k) \geq & q_{k}\left(z \omega_{i}^{R}\left(v, c^{\beta}, k\right)+(1-z) \omega_{i}^{R}(v, \bar{c}, k)\right)+\left(1-q_{k}\right) \omega_{i}^{C}(v, k),
\end{aligned}
$$

or, equivalently,

$$
\begin{aligned}
\omega_{i}^{R}(v, \bar{c}, k) & \geq b_{i}, \\
b_{i} & =\left\{\begin{array}{cc}
\frac{q_{k} z \omega_{i}^{R}\left(v, c^{\beta}, k\right)+\left(1-q_{k}\right) \omega_{i}^{C}(v, k)}{1-q_{k}(1-z)} & \text { if } q_{k}(1-z)<1 \\
-\infty & \text { otherwise. }
\end{array}, i \in\{1,2\} .\right.
\end{aligned}
$$

where condition (28) is obtained by comparing the reorganization payoff with the expected outcome when one of the followers accept the plan, while the other rejects it (see Table 1).

$D=(A, R)$ or $(R, A)$ If Follower 1 accepts the plan while Follower 2 rejects it, then the outcome vector is

$$
q_{k}\left(z \omega^{R}\left(v, c^{\beta}, k\right)+(1-z) \omega^{R}(v, c, k)\right)+\left(1-q_{k}\right) \omega^{C}(v, k) .
$$


The leader's best proposal in that case is the solution of

$$
\max _{\bar{c}}\left\{\omega_{0}^{R}(v, \bar{c}, k)\right\}
$$

s.t.

$q_{k}\left(z \omega_{1}^{R}\left(v, c^{\beta}, k\right)+(1-z) \omega_{1}^{R}(v, \bar{c}, k)\right)+\left(1-q_{k}\right) \omega_{1}^{C}(v, k)$

$\geq q_{k} \omega_{1}^{L}(v, k)+\left(1-q_{k}\right) \omega_{1}^{C}(v, k)$

and

$$
\begin{aligned}
& q_{k}\left(z \omega_{2}^{R}\left(v, c^{\beta}, k\right)+(1-z) \omega_{2}^{R}(v, \bar{c}, k)\right)+\left(1-q_{k}\right) \omega_{2}^{C}(v, k) \\
& \geq \omega_{2}^{R}(v, \bar{c}, k)
\end{aligned}
$$

or equivalently

$$
\begin{aligned}
\omega_{1}^{R}(v, \bar{c}, k) & \geq b_{1}, \\
b_{1} & =\left\{\begin{aligned}
\frac{\omega_{1}^{L}(v, k)-z \omega_{1}^{R}\left(v, c^{\beta}, k\right)}{1-z} & \text { if } z<1 \text { and } q_{k}>0 \\
-\infty & \text { otherwise }
\end{aligned}\right.
\end{aligned}
$$

and

$$
\begin{aligned}
\omega_{2}^{R}(v, \bar{c}, k) & \leq b_{2}, \\
b_{2} & =\left\{\begin{array}{l}
\frac{q_{k} z \omega_{2}^{R}\left(v, c^{\beta}, k\right)+\left(1-q_{k}\right) \omega_{2}^{C}(v, k)}{1-q_{k}(1-z)} \quad \text { if } q_{k}(1-z)<1 \\
q_{k} \omega_{2}^{R}\left(v, c^{\beta}, k\right)+\left(1-q_{k}\right) \omega_{2}^{C}(v, k) \quad \text { otherwise. }
\end{array}\right.
\end{aligned}
$$

where the constraints are obtained by comparing what Follower 1 may expect if he rejects the plan and what Follower 2 may expect if he accepts the plan. The leader's best proposal corresponding to the decision pair $(R, A)$ is obtained by changing the identity of the followers.

$D=(R, R)$ If both followers reject the plan, the outcome vector is

$$
q_{k} \omega^{L}(v, k)+\left(1-q_{k}\right) \omega^{C}(v, k)
$$


which does not depend on the coupon proposed by the leader, as long as it leads the followers to reject the plan. It suffices that the leader propose nothing to both followers to achieve this outcome.

The optimization problems (27)-(28) and (31)-(32) involve the reorganization values $\omega_{i}^{R}$. Using the auxiliary variable $y$ defined in (20) and differentiating (24) with respect to $y$ yields

$$
-\frac{w_{k}}{\lambda}\left(1-y^{\frac{\lambda}{1-\lambda}}\right)<0 \text { if } y \in[0,1]
$$

which shows that the reorganization value of the equityholder is decreasing in $y$ on $[0,1]$, with $\omega_{e}^{R}(v, 0, k)=w_{k}$ and $\omega_{e}^{R}(v, 1, k)=0$. Similarly, it is straightforward to verify that the total creditors' reorganization value $\omega_{d}^{R}(v, y, k)$ is concave in $y$ and admits a maximum at

$$
y^{*}=\left(\frac{1-\lambda}{1-\lambda(1-\tau)(1-\alpha)}\right)^{(1-\lambda) / \lambda} \in[0,1],
$$

with $\omega_{d}^{R}(v, 0, k)=0$ and $\omega_{d}^{R}(v, 1, k)=w_{k}(1-\alpha)$. These properties of the reorganization values allow to characterize the leader's optimal plan analytically at any $(v, k)$.

\section{Equityholder's plan}

$D=(A, A)$ When the leader is the equityholder, the solution of problem (27)-(28) is obtained by offering the lower bound on their payoff to both followers, as defined by (29). The optimal reorganization plan for the equityholder is therefore obtained by solving for $y$ the following:

$$
\omega_{d}^{R}(v, y, k)=b_{s}+b_{j},
$$

where $\omega_{d}^{R}(v, y, k) \in\left[0, w_{k}(1-\alpha)\right]$.

i If $0<b_{s}+b_{j}<w_{k}(1-\alpha)$, then there is a unique $y \in(0,1)$ corresponding to a unique total coupon satisfying (36), which is the solution to problem (27)-(28).

ii If $w_{k}(1-\alpha)<b_{s}+b_{j}$ while $\omega_{d}^{R}\left(v, y^{*}, k\right)$ is positive, then there are two values satisfying (36); Since the share of the equityholder is decreasing in $y$, the smallest of these two values is the solution to problem (27)-(28). 
iii If $w_{k}(1-\alpha)<b_{s}+b_{j}$ while $\omega_{d}^{R}\left(v, y^{*}, k\right)$ is negative, then the equityholder is not able to offer their lower bounds to the creditors, and it is not possible for him to propose a plan that will be accepted by both creditors.

iv If $b_{s}+b_{j} \leq 0$ while $w_{k}(1-\alpha)>b_{s}+b_{j}$, then the solution to problem (27)-(28) is $y=c=0$.

The relative share of the total coupon which is offered to the senior and junior creditors can then easily be determined by solving (9) for the senior debt coupon $c_{s}$, given $y$.

$D=(A, R)$ or $(R, A)$ The solution of problem (31)-(32) is obtained by offering the lower bound $b_{1}$ in (33) to Follower 1, and nothing to Follower 2. First, select the identity of Follower 1 by choosing

$$
\arg \min _{i \in\{s, j\}}\left\{\omega_{i}^{L}(v, k)-z \omega_{i}^{R}\left(v, c^{\beta}, k\right)\right\} .
$$

The optimal reorganization plan for the equityholder is then obtained by solving for $y$ the following:

$$
\omega_{d}^{R}(v, y, k)=b_{1}
$$

using (13). If $0<b_{1}<w_{k}(1-\alpha)$, then there is a unique $y \in[0,1]$ corresponding to a unique coupon satisfying (38), which is the solution to problem (31)-(32); the other possible cases are obtained similarly as for problem (27)-(28) above.

\section{Creditor's plan}

If the leader is one of the creditors, he maximizes his share in the reorganized firm by deciding both on the total coupon and on the relative share of the other creditor, which we will label $f$. For a given total coupon, the leader's objective function is decreasing in the share of the other creditor, so that it is optimal to offer Creditor $f$ the lower bound on his payoff. Therefore, the objective functions (27) and (31) can both be written:

$$
\omega_{d}^{R}(v, y, k)-b_{f}
$$

where $\omega_{d}^{R}(v, y, k)$ is a concave function in $y$ admitting a maximum at $y^{*}$ defined in (35). 
$D=(A, A)$ In problem (27)-(28), the followers' payoffs $b_{f}$ and $b_{e}$ are defined by (29).

i If $\omega_{d}^{R}\left(v, y^{*}, k\right)<b_{f}$, then it is not possible for the leader to offer a plan that will be accepted by both followers.

Otherwise, if $\omega_{d}^{R}\left(v, y^{*}, k\right) \geq b_{f}$, then we check if plan $y^{*}$ satisfies the equityholders or not.

ii If $\omega_{e}^{R}\left(v, y^{*}, k\right) \geq b_{e}$, then the optimal plan corresponds to $y^{*}$. The relative share of the two creditors in the reorganized coupon is obtained by solving $\omega_{f}^{R}\left(v, y^{*}, k\right)=b_{f}$.

iii If $\omega_{e}^{R}\left(v, y^{*}, k\right)<b_{e}$, the leader has to offer $b_{e}$ to the equityholders, by proposing a plan that solves

$$
\frac{w_{k}}{\lambda}\left(\lambda-y+(1-\lambda) y^{\frac{1}{1-\lambda}}\right)=b_{e}
$$

Since the equity value is decreasing in $y$, then if $w_{k} \geq b_{e}$, there is a unique solution in $[0,1]$ to $(40)$, denoted $y^{b}$. If $\omega_{d}^{R}\left(v, y^{b}, k\right) \geq b_{f}$, the optimal plan for the leader is $y^{b}$ and the relative share of the two creditors in the reorganized coupon is obtained by solving

$$
\omega_{f}^{R}\left(v, y^{b}, k\right)=b_{f}
$$

iv If $w_{k}<b_{e}$ or $\omega_{d}^{R}\left(v, y^{b}, k\right)<b_{f}$, then it is not possible for the leader to offer a plan that will be accepted by both followers.

$D=(A, R)$ or $(R, A) \quad$ The solution of problem (31)-(32) depends on the identity of Follower 1, who accepts the plan. The leader chooses the identity of Follower 1 by comparing his share in the two following cases.

i If Follower 1 is the equityholder, then the leader maximizes his share by offering nothing to the other creditor, $c_{f}=0$. If $\omega_{e}^{R}\left(v, y^{*}, k\right) \geq b_{e}$, then the optimal plan corresponds to $y^{*}$, whereas if $\omega_{e}^{R}\left(v, y^{*}, k\right)<b_{e}$ and $w_{k} \geq b_{e}$, then the optimal plan corresponds to $y^{b}$. If $w_{k}<b_{e}$, it is not possible for the leader to offer a plan that will be accepted by Follower 1 . 
ii If Follower 1 is the other creditor, then if $\omega_{d}^{R}\left(v, y^{*}, k\right)<b_{f}$, it is not possible for the leader to offer a plan that will be accepted by Follower 1. Otherwise, the leader maximizes his share by proposing plan $y^{*}$, and the relative share of the two creditors is obtained by solving (41).

\section{Appendix B: Numerical implementation}

The value of what each claimant expects to recover from the Chapter 11 negotiation procedure at a given date $t=k d, k=0, \ldots, K$ is a function of the value of the firm's assets at that date obtained by solving the stochastic dynamic program (??)-(??) by backward induction from the last negotiation round, using (21), (16) and (17). Since the state space of the dynamic program is continuous, the first step is to partition it into a collection of convex subsets, and obtain a corresponding finite set of grid points where the value functions are to be evaluated. Piecewise-linear continuous interpolation functions are then defined to approximate the value functions over the state space.

Let $g_{0}<g_{1}<\ldots<g_{m}<\ldots<g_{M}$ define a grid $\mathcal{G}$ on the space of asset values, and let $g_{0}=0$ and $g_{M+1}=+\infty$. Assume that approximations of the value functions, denoted by $\tilde{\omega}_{i}, i \in\{s, j, e\}$, are known on $\mathcal{G}$. We define continuous piecewise linear interpolation functions $\hat{\omega}_{i}$ on $\mathbb{R}$ such that at $t=k d, \hat{\omega}_{i}(v, k)=\tilde{\omega}_{i}(v, k)$ on $\mathcal{G}$ and

$$
\begin{aligned}
\hat{\omega}_{i}(v, k) & =\left\{\begin{array}{cc}
0 & \text { for } v<g_{0} \\
a_{i m}^{k}+h_{i m}^{k} v & \text { for } g_{m} \leq v \leq g_{m+1}, m=0, \ldots, M
\end{array}\right. \\
& =\sum_{m=0}^{M}\left(a_{i m}^{k}+h_{i m}^{k} v\right) \mathbf{1}\left(g_{m} \leq v<g_{m+1}\right)
\end{aligned}
$$

where $\mathbf{1}(\cdot)$ is the indicator function.

The coefficients $a_{i m}^{k}$ and $h_{i m}^{k}$ of the piecewise linear interpolation functions are obtained by setting $\hat{\omega}_{i}(v, k)=\tilde{\omega}_{i}(v, k)$ on the grid and by extrapolating outside the grid. They are 
given by

$$
\begin{aligned}
a_{i 0}^{k} & =0 \\
h_{i 0}^{k} & =\frac{\tilde{\omega}_{i}\left(g_{1}, k\right)}{g_{1}} \\
a_{i m}^{k} & =\frac{g_{m+1} \tilde{\omega}_{i}\left(g_{m}, k\right)-g_{m} \tilde{\omega}_{i}\left(g_{m+1}, k\right)}{g_{m+1}-g_{m}}, m=1, \ldots, M-1 \\
h_{i m}^{k} & =\frac{\tilde{\omega}_{i}\left(g_{m+1}, k\right)-\tilde{\omega}_{i}\left(g_{m}, k\right)}{g_{m+1}-g_{m}}, m=1, \ldots, M-1 \\
a_{i M}^{k} & =a_{i M-1}^{k} \\
h_{i M}^{k} & =h_{i M-1}^{k} .
\end{aligned}
$$

Using the interpolated value functions in (42) at $v=g_{n}, n=1, \ldots M$, yields for $k=$ $0, \ldots, K-1$ and $t=k d$

$$
\begin{aligned}
& e^{-r d} \mathbb{E}_{v t}\left[\hat{\omega}_{i}\left(V_{t+d}, k+1\right)\right] \\
= & e^{-r d} \mathbb{E}_{v t}\left[\sum_{m=0}^{M}\left(a_{i m}^{k+1}+h_{i m}^{k+1} V_{t+d}\right) \mathcal{I}_{m}\right] \\
= & \sum_{m=0}^{M} A_{n m} \tilde{\omega}_{i}\left(g_{m}, k+1\right)
\end{aligned}
$$

where $\mathcal{I}_{m}$ denotes the indicator function of the event $\left\{g_{m} \leq V_{t+d}<g_{m+1}\right\}$. Using (43), the transition parameters $A_{n m}$, from state $v=g_{n}$ at $t$ to the interval $\left[g_{m}, g_{m+1}\right)$ at $t+d$, which are constant under our assumption of equal length negotiation rounds, are then given by

$$
A_{n m}=\left\{\begin{array}{c}
e^{-r d} \mathbb{E}_{v t}\left[\frac{g_{1}-V_{t+d}}{g_{1}-g_{0}} \mathcal{I}_{0}\right] \text { for } m=0 \\
e^{-r d} \mathbb{E}_{v t}\left[\frac{V_{t+d}-g_{m-1}}{g_{m}-g_{m-1}} \mathcal{I}_{m-1}+\frac{g_{m+1}-V_{t+d}}{g_{m+1}-g_{m}} \mathcal{I}_{m}\right] \text { for } 1 \leq m<M \\
e^{-r d} \mathbb{E}_{v t}\left[\frac{V_{t+d}-g_{m-1}}{g_{m}-g_{m-1}}\left(\mathcal{I}_{m-1}+\mathcal{I}_{m}\right)\right] \text { for } m=M
\end{array}\right.
$$

Recall that, according to our assumption (1) about the assets value process, at $v=g_{n}$

$$
\begin{aligned}
\mathbb{E}_{v t}\left(\mathcal{I}_{m}\right) & =\Phi\left(x_{n, m+1}\right)-\Phi\left(x_{n m}\right) \\
\mathbb{E}_{v t}\left(V_{t+d} \mathcal{I}_{m}\right) & =g_{n}\left(\Phi\left(x_{n, m+1}-\sigma \sqrt{d}\right)-\Phi\left(x_{n m}-\sigma \sqrt{d}\right)\right)
\end{aligned}
$$


where $\Phi$ is the standard normal cumulative distribution function and

$$
x_{n m}=\frac{\ln \left(\frac{g_{m}}{g n}\right)-\left(r-\frac{\sigma^{2}}{2}\right) d}{\sigma \sqrt{d}} .
$$

The algorithm to compute the value vector of the $K$-stage, three player game is then the following.

\section{Algorithm}

1. Initialization

(a) Read parameter values. Define $\mathcal{G}$, the grid on the asset's space.

(b) For $n=1, \ldots, M$ and $m=0, \ldots, M$, compute the transition parameters $A_{n m}$ according to (45)-(46)

2. Negotiation rounds

(a) Set $\omega_{i}^{C}(v)=0, i \in\{s, j, e\}$ and $k=K$. Set the identity of the leader at round $K$

(b) For $v=g_{1}, \ldots, g_{M}$

i. If $v \leq C_{k}$, then the firm is liquidated and $\omega_{i}^{*}(v, k)=0, i \in\{0,1,2\}$

ii. Otherwise compute the equilibrium outcome of negotiation round $k$

A. Compute the liquidation value vector $\omega^{L}(v, k)$ according to (4)-(6)

B. Compute the judge coupon $c^{\beta}$ according to (26) and the emergence value vector under the judge's plan, $\omega^{R}\left(v, c^{\beta}, k\right)$, according to (9), (??) and (14)

C. Solve problem (27) as in (7) or (7) according to the identity of the leader

D. Solve problem (31) as in Appendix (7) or (7) according to the identity of the leader

E. Compare the leader's payoff for the four possible decision pairs of the follower. Record the equilibrium strategies $\chi_{i}(v, k)$ and outcomes $\tilde{\omega}_{i}(v, k)=$ $\omega_{i}^{*}(v, k), i \in\{0,1,2\}$ according to $(21)$ 
3. Continuation values

(a) for $v=g_{n}, n=0, \ldots, M$ and $i \in\{s, j, e\}$, set

$$
\tilde{\omega}_{i}^{C}(v, 0)=\sum_{m=0}^{M} A_{n m} \tilde{\omega}_{i}\left(g_{m}, k+1\right)
$$

(b) Set $k=k-1$

(c) If $k=0$, stop. the equilibrium value function is given by $\tilde{\omega}_{i}^{C}(v, 0)$

(d) Otherwise, identify the leader at round $k$ and go to step $2 \mathrm{~b}$.

\section{Appendix C: Equilibrium probabilities}

In our simulations, the number of domains varies from 2 to 4 , depending on parameter values. To keep the exposition concise, we will detail the calculations for parameterizations that yield three different domains: One domain is liquidation for asset value $v \in\left(0, C_{k}\right)$, another one is reorganization under the leader's plan for asset value $v \in\left(C_{k}, a_{k}\right)$, and a last one is negotiation continuation for asset value $v \in\left(a_{k},+\infty\right)$. The critical level $a_{k}$ is numerically determined by the dynamic programming algorithm.

We define the following thresholds at which standard normal cumulative distribution functions are evaluated

$$
\begin{aligned}
x_{k}= & \frac{\ln \frac{V_{0}}{a_{k}}+\left(\mu-\frac{\sigma^{2}}{2}\right) k d}{\sigma \sqrt{k d}}, \\
y_{k}= & \frac{\ln \frac{V_{0}}{C_{k}}+\left(\mu-\frac{\sigma^{2}}{2}\right) k d}{\sigma \sqrt{k d}} .
\end{aligned}
$$

We denote $\Phi_{n}\left(\{h\} ;\left\{\rho_{i j}\right\}\right)$ the multivariate standard normal cumulative distribution function evaluated at thresholds $\{h\}$ with correlation coefficients $\left\{\rho_{i j}\right\}$.

Liquidation probabilities Liquidation occurs at the first round iff $V_{d} \leq C_{1}$. It occurs at the second round iff $V_{d}>a_{1}$, the judge does not cramdown and $V_{2 d} \leq C_{2}$. It occurs at the third round iff $V_{d}>a_{1}, V_{2 d}>a_{2}$, the judge does not cramdown during the 
first two rounds, and $V_{3 d} \leq C_{3}$ or $V_{3 d}>a_{3}$ and the judge does not cramdown. Liquidation probabilities for the three rounds are therefore given by

$$
\begin{aligned}
\Pi_{L 1}= & \Phi_{1}\left(-y_{1}\right) \\
\Pi_{L 2}= & \left(1-q_{1}\right) \Phi_{2}\left(x_{1},-y_{2} ;-\rho_{12}\right), \\
\Pi_{L 3}= & \left(1-q_{1}\right)\left(1-q_{2}\right) \Phi_{3}\left(x_{1}, x_{2},-y_{3} ; \rho_{12},-\rho_{13},-\rho_{23}\right) \\
& +\left(1-q_{1}\right)\left(1-q_{2}\right)\left(1-q_{3}\right) \Phi_{3}\left(x_{1}, x_{2}, x_{3} ; \rho_{12}, \rho_{13}, \rho_{23}\right) .
\end{aligned}
$$

where the correlation coefficients between the Brownian motion at rounds one and two, one and three, and two and three, are given by

$$
\rho_{12}=\sqrt{\frac{d}{2 d}}=\frac{1}{\sqrt{2}}, \rho_{13}=\sqrt{\frac{d}{3 d}}=\frac{1}{\sqrt{3}}, \rho_{23}=\sqrt{\frac{2 d}{3 d}}=\frac{\sqrt{2}}{\sqrt{3}} .
$$

Cramdown probabilities The judge imposes a reorganization plan at the first round when $V_{d}>a_{1}$ with probability $q_{1}$. She imposes a plan at the second round when $V_{d}>a_{1}$, she does not cramdown at the first round, and when $V_{2 d}>a_{2}$ with probability $q_{2}$. She imposes a plan at the third round when $V_{d}>a_{1}, V_{2 d}>a_{2}$, she does not cramdown during the first two rounds, and when $V_{3 d}>a_{3}$ with probability $q_{3}$. Cramdown probabilities for the three rounds are therefore given by

$$
\begin{aligned}
& \Pi_{C 1}=q_{1} \Phi_{1}\left(x_{1}\right) \\
& \Pi_{C 2}=\left(1-q_{1}\right) q_{2} \Phi_{2}\left(x_{1}, x_{2} ; \rho_{12}\right) \\
& \Pi_{C 3}=\left(1-q_{1}\right)\left(1-q_{2}\right) q_{3} \Phi_{3}\left(x_{1}, x_{2}, x_{3} ; \rho_{12}, \rho_{13}, \rho_{23}\right) .
\end{aligned}
$$

Reorganization (under the Leader's plan) probabilities The firm is reorganized under the shareholders' plan at the first round iff $V_{d}>C_{1}$ and $V_{d} \leq a_{1}$. It is reorganized under the junior creditors' plan at the second round iff $V_{d}>a_{1}$, the judge does not cramdown and $V_{2 d}>C_{2}$ and $V_{2 d} \leq a_{2}$. It is reorganized under the senior creditors' plan at the third round iff $V_{d}>a_{1}, V_{2 d}>a_{2}$, the judge does not cramdown during the first two rounds, and 
$V_{3 d}>C_{3}$ and $V_{3 d} \leq a_{3}$. Reorganization (under the Leader's plan) probabilities for the three rounds are therefore given by

$$
\begin{aligned}
\Pi_{R 1}= & \Phi_{1}\left(-x_{1}\right)-\Phi_{1}\left(-y_{1}\right), \\
\Pi_{R 2}= & \left(1-q_{1}\right)\left[\Phi_{1}\left(x_{1}\right)-\Phi_{2}\left(x_{1}, x_{2} ; \rho_{12}\right)-\Phi_{2}\left(x_{1},-y_{2} ;-\rho_{12}\right)\right], \\
\Pi_{R 3}= & \left(1-q_{1}\right)\left(1-q_{2}\right)\left[\Phi_{2}\left(x_{1}, x_{2} ; \rho_{12}\right)-\Phi_{3}\left(x_{1}, x_{2}, x_{3} ; \rho_{12}, \rho_{13}, \rho_{23}\right)\right. \\
& \left.-\Phi_{3}\left(x_{1}, x_{2},-y_{3} ; \rho_{12},-\rho_{13},-\rho_{23}\right)\right] .
\end{aligned}
$$

One can verify that the probability that renegotiation carries on to the second round, which is $\left(1-q_{1}\right) \Phi_{1}\left(x_{1}\right)$, is actually equal to

$$
1-\Pi_{L 1}-\Pi_{C 1}-\Pi_{R 1}
$$

Similarly, the probability that renegotiation carries on to the third round, which is

$$
\left(1-q_{1}\right)\left(1-q_{2}\right) \Phi_{2}\left(x_{1}, x_{2} ; \rho_{12}\right)
$$

is actually equal to

$$
\left(1-q_{1}\right) \Phi_{1}\left(x_{1}\right)-\Pi_{L 2}-\Pi_{C 2}-\Pi_{R 2}
$$

Finally, the probability that renegotiation carries on to the third round must also be equal to

$$
\Pi_{L 3}+\Pi_{C 3}+\Pi_{R 3} .
$$




\section{Figure}

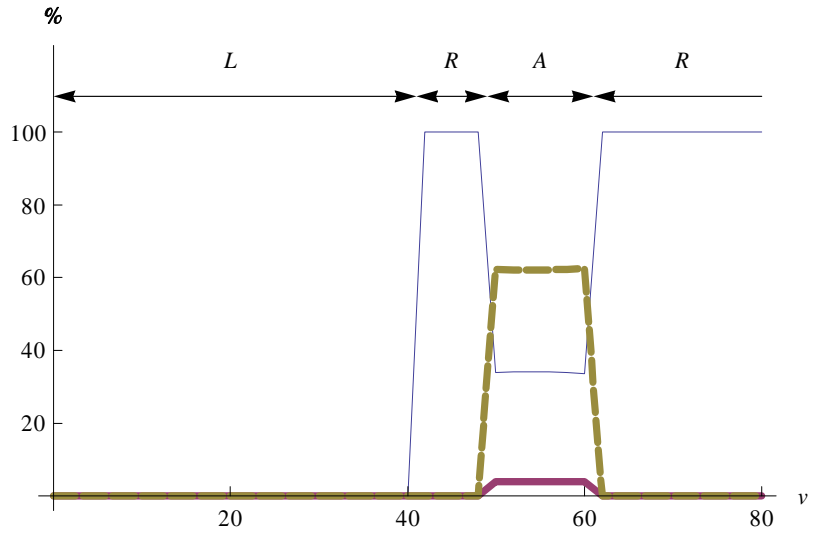

Figure 1a: Shareholders' plans

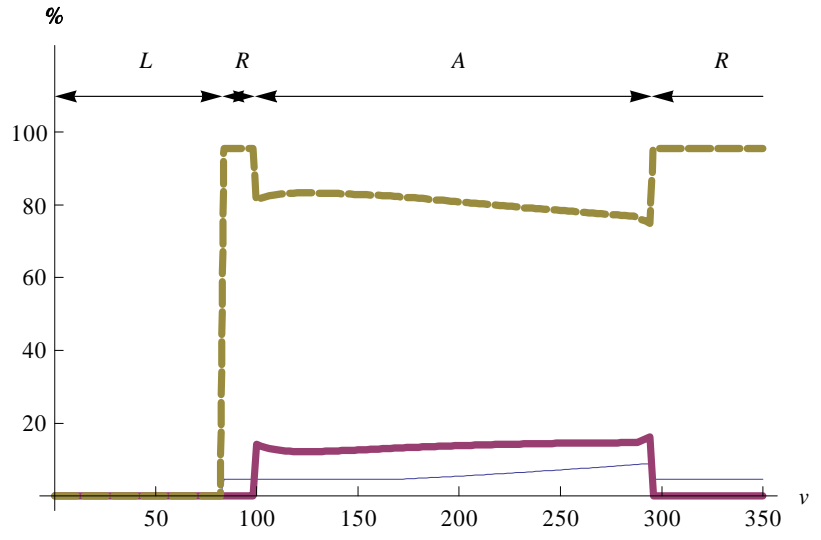

Figure 1b: Senior creditors' plans

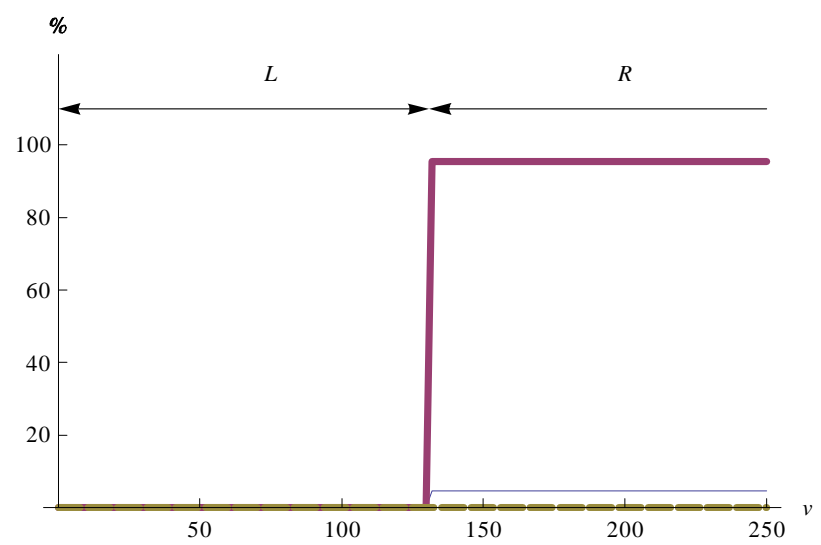

Figure 1c: Junior creditors' plans

Figure 1: Allocation of firm value proposed by claimholders as a function of asset value.

Figures 1a, 1b, and 1c show the fractions (in percentage) of firm value offered to the three classes of claimholders, as a function of asset value. The thin line represents the share of equityholders, the dashed line represents that of senior creditors, and the thick line represents that of junior creditors. In figure 1a, the fractions are set according to the plan proposed by shareholders in the first round. In figure $1 \mathrm{~b}$, they are set according to the plan proposed by senior creditors in the second round. In figure 1c, they are set according to the plan proposed by junior creditors in the third round. For each proposed plan, the arrows on top of the figures indicate the equilibrium domain: $L$ means the firm is liquidated, $R$ means the plan is rejected, and $A$ means the plan is accepted. Parameters are set as in Table 3. 


\section{Tables}

\begin{tabular}{|c|c|c|c|}
\hline & & \multicolumn{2}{|c|}{ Follower 2} \\
\hline & & $A$ & $R$ \\
\hline \multirow{2}{*}{$\begin{array}{c}\text { Follower } \\
1\end{array}$} & $A$ & $\omega^{R}(v, c)$ & $\begin{array}{c}q_{k}\left[z \omega^{R}\left(v, c^{\beta}\right)+(1-z) \omega^{R}(v, c)\right] \\
+\left(1-q_{k}\right) \theta \omega^{C}(v, k)\end{array}$ \\
\hline & $R$ & $\begin{array}{c}q_{k}\left[z \omega^{R}\left(v, c^{\beta}\right)+(1-z) \omega^{R}(v, c)\right] \\
+\left(1-q_{k}\right) \theta \omega^{C}(v, k)\end{array}$ & $q_{k} L \omega^{L}\left(v, c^{0}\right)+\left(1-q_{k}\right) \theta \omega^{C}(v, k)$ \\
\hline
\end{tabular}

Table 1: Normal form representation of the game at a given round $k$.

This table shows the outcomes of a negotiation game at any given round $k$, when the Leader proposes a reorganization plan to Follower 1 and Follower 2. The followers decide separately whether to accept $(\mathrm{A})$ or reject $(\mathrm{R})$ the plan, which consists in proposing a new reorganized coupons $c$ to the creditors. If both followers accept the Leader's plan, then the firm is reorganized and the reorganized coupons are distributed. If both followers reject the plan, then the firm is liquidated by the bankruptcy judge with a probability $q_{k}$, and the game moves to the next bargaining round otherwise. Finally, if the followers take opposite decisions on the Leader's plan, then the firm is reorganized by the judge with a probability $q_{k}$. In this case, she imposes her own reorganization plan with a probability $z$, and implements the Leader's plan with a probability $(1-z)$. 


\begin{tabular}{lcc}
\hline \hline & $\begin{array}{c}\text { Number } \\
\text { of filings }\end{array}$ & $\begin{array}{c}\text { Percentage } \\
\text { of filings }\end{array}$ \\
\hline Panel A: Distribution of filing & dates \\
\hline 1997 & 2 & 3.05 \\
1998 & 12 & 1.53 \\
1999 & 16 & 9.16 \\
2000 & 35 & 12.21 \\
2001 & 33 & 26.72 \\
2002 & 14 & 25.19 \\
2003 & 4 & 10.69 \\
2004 & 9 & 3.05 \\
2005 & 2 & 6.87 \\
2006 & 0 & 1.53 \\
2007 & & 0 \\
\hline Panel B: Distribution of firms industries \\
\hline Transportation & 46 & 35.11 \\
and public utilities & 2 & 1.53 \\
Mining & 2 & 1.53 \\
Construction & 36 & 27.48 \\
Manufacturing & 5 & 3.82 \\
Wholesale trade & 15 & 11.45 \\
Retail trade & 20 & 15.27 \\
Services & 5 & 3.82 \\
Others &
\end{tabular}

Table 2: Descriptive statistics on the sample of Chapter 11 filings.

The data is provided by Compustat and www.bankruptcydata.com, and consists in a sample of 131 Chapter 11 filings by 128 firms between 1997 and 2007. Panel A shows the distribution of filings by year of filing. Panel B provides information on the industry distribution of the filings according to their SIC code. 


\begin{tabular}{lcc}
\hline \hline \multicolumn{1}{c}{ Description } & Notation & Base value \\
\hline Risk-free interest rate & $r$ & $4 \%$ \\
\hline Firm-specific parameters & $\mu$ & \\
\hline Assets return during Chapter 11 (\%) & $\sigma$ & $1.5 \%$ \\
Asset return volatility (\%) & $V$ & $35 \%$ \\
Asset value at the entry in Chapter 11 & $c$ & 100 \\
Coupon level & $\xi$ & $80 \%$ \\
Share of senior coupon & $\tau$ & $30 \%$ \\
Net tax advantage of debt after emergence & $\delta$ & $2 \%$ \\
Payout rate after emergence & & \\
\hline Bankruptcy-specific parameters & $d$ & 2 \\
\hline Length of a negotiation round & $K$ & 3 \\
Number of negotiation rounds & $q$ & $\left(\frac{3}{4}, \frac{3}{4}, \frac{3}{4}\right)$ \\
Judge's impatience & $z$ & 0.5 \\
Probability that the judge imposes her own plan & $\beta_{i}$ & $\frac{1}{3}$ \\
Claimant $i=\{s, j, e\}$ bargaining power & $\alpha$ & $2 \%$ \\
Liquidation costs & $\theta$ & $20 \%$ \\
Financial distress costs & & \\
\hline \hline
\end{tabular}

Table 3: Parameters resulting from model calibration.

This table reports base case values for the model parameters. Firm-specific parameters (except for the net tax advantage of debt) are estimated from a sample of 131 Chapter 11 filings over the period 1997-2007. They are computed using quarterly data over a period of two years prior to the filing date (annual data is used for the share of senior coupon). Bankruptcy-specific parameters are chosen to be consistent with reported Chapter 11 durations. Liquidation and financial distress costs are obtained from Bris et al. (2006). 


\begin{tabular}{llccc}
\hline \hline & Liquidation & \multicolumn{2}{c}{ Reorganization probability $(\%)$} \\
\cline { 3 - 5 } & probability & under & under \\
& $(\%)$ & Leader plan & Judge plan \\
\hline Base case & Total & $\mathbf{1 4 . 3 6}$ & $\mathbf{5 2 . 4 2}$ & $\mathbf{3 3 . 2 2}$ \\
& Per round & {$[4.80,8.99,0.57]$} & {$[42.04,10.26,0.12]$} & {$[31.89,1.20,0.12]$} \\
$\mu=1 \%$ & Total & $\mathbf{1 4 . 7 4}$ & $\mathbf{5 2 . 2 3}$ & $\mathbf{3 3 . 0 3}$ \\
& Per round & {$[5.01,9.17,0.56]$} & {$[42.10,10.02,0.11]$} & {$[31.73,1.18,0.11]$} \\
$\mu=3 \%$ & Total & $\mathbf{1 3 . 2 6}$ & $\mathbf{5 2 . 9 8}$ & $\mathbf{3 3 . 7 7}$ \\
& Per round & {$[4.23,8.46,0.57]$} & {$[41.86,10.98,0.14]$} & {$[32.35,1.28,0.14]$} \\
$\sigma=25 \%$ & Total & $\mathbf{2 . 1 8}$ & $\mathbf{8 1 . 0 1}$ & $\mathbf{1 6 . 8 1}$ \\
& Per round & {$[0.62,1.47,0.09]$} & {$[71.80,9.17,0.03]$} & {$[16.54,0.24,0.03]$} \\
$\sigma=45 \%$ & Total & $\mathbf{2 4 . 1 9}$ & $\mathbf{4 0 . 7 5}$ & $\mathbf{3 5 . 0 7}$ \\
& Per round & {$[12.13,11.20,0.86]$} & {$[32.95,7.59,0.21]$} & {$[32.95,1.91,0.21]$} \\
\multirow{2}{*}{$c=8$} & Total & $\mathbf{1 4 . 3 9}$ & $\mathbf{5 2 . 1 9}$ & $\mathbf{3 3 . 4 2}$ \\
& Per round & {$[4.80,8.99,0.60]$} & {$[42.04,9.99,0.16]$} & {$[31.89,1.37,0.16]$} \\
$c=12$ & Total & $\mathbf{1 4 . 3 5}$ & $\mathbf{5 2 . 5 0}$ & $\mathbf{3 3 . 1 5}$ \\
& Per round & {$[4.80,8.99,0.55]$} & {$[42.04,10.35,0.11]$} & {$[31.89,1.15,0.11]$} \\
$\xi=70 \%$ & Total & $\mathbf{1 4 . 3 8}$ & $\mathbf{5 2 . 2 7}$ & $\mathbf{3 3 . 3 5}$ \\
& Per round & {$[4.80,8.99,0.59]$} & {$[42.04,10.08,0.14]$} & {$[31.89,1.31,0.14]$} \\
$\xi=90 \%$ & Total & $\mathbf{1 4 . 3 5}$ & $\mathbf{5 2 . 5 3}$ & $\mathbf{3 3 . 1 2}$ \\
& Per round & {$[4.80,8.99,0.55]$} & {$[42.04,10.39,0.10]$} & {$[31.89,1.13,0.10]$} \\
\hline \hline
\end{tabular}

Table 4: Equilibrium probabilities for different model calibrations with respect to firm-specific parameters.

This table reports liquidation and reorganization (under Leader or judge plan) probabilities over the whole Chapter 11 procedure as well as for each round. Probabilities are given for the base case and for deviations from the base case as one firm-specific parameter value is changed at a time. 


\begin{tabular}{|c|c|c|c|c|}
\hline & & \multirow{3}{*}{$\begin{array}{c}\text { Liquidation } \\
\text { probability } \\
(\%)\end{array}$} & \multicolumn{2}{|c|}{ Reorganization probability (\%) } \\
\hline & & & under & under \\
\hline & & & Leader plan & Judge plan \\
\hline \multirow[t]{2}{*}{ Base case } & Total & 14.36 & 52.42 & 33.22 \\
\hline & Per round & {$[4.80,8.99,0.57]$} & {$[42.04,10.26,0.12]$} & {$[31.89,1.20,0.12]$} \\
\hline \multirow[t]{2}{*}{$d=1$} & Total & 1.47 & 58.62 & 39.90 \\
\hline & Per round & {$[0.00,1.05,0.42]$} & {$[38.09,20.00,0.53]$} & {$[37.14,2.23,0.53]$} \\
\hline \multirow[t]{2}{*}{$d=3$} & Total & 40.00 & 31.55 & 28.45 \\
\hline & Per round & {$[27.79,11.62,0.59]$} & {$[27.08,4.35,0.12]$} & {$[27.08,1.25,0.12]$} \\
\hline \multirow[t]{2}{*}{$z=0.35$} & Total & 17.25 & 55.23 & 27.52 \\
\hline & Per round & {$[4.80,11.14,1.31]$} & {$[46.41,8.28,0.54]$} & {$[24.99,2.24,0.29]$} \\
\hline \multirow[t]{2}{*}{$z=0.65$} & Total & 7.46 & 70.50 & 22.04 \\
\hline & Per round & {$[4.80,2.44,0.22]$} & {$[63.00,7.45,0.04]$} & {$[21.28,0.67,0.09]$} \\
\hline \multirow[t]{2}{*}{$\alpha=1 \%$} & Total & 14.74 & 51.32 & 33.94 \\
\hline & Per round & {$[4.80,9.37,0.58]$} & {$[40.88,10.32,0.12]$} & {$[32.59,1.23,0.12]$} \\
\hline \multirow[t]{2}{*}{$\alpha=3 \%$} & Total & 14.36 & 52.42 & 33.22 \\
\hline & Per round & {$[4.80,8.99,0.57]$} & {$[42.04,10.26,0.12]$} & {$[31.89,1.20,0.12]$} \\
\hline \multirow[t]{2}{*}{$\theta=10 \%$} & Total & 4.45 & 54.55 & 41.00 \\
\hline & Per round & {$[0.11,3.49,0.85]$} & {$[38.01,15.89,0.65]$} & {$[37.13,3.22,0.65]$} \\
\hline \multirow[t]{2}{*}{$\theta=30 \%$} & Total & 29.61 & 46.03 & 24.36 \\
\hline & Per round & {$[19.90,9.35,0.36]$} & {$[40.84,5.12,0.07]$} & {$[23.55,0.74,0.07]$} \\
\hline
\end{tabular}

Table 5: Equilibrium probabilities for different model calibrations with respect to bankruptcy-specific parameters.

This table reports liquidation and reorganization (under Leader or judge plan) probabilities over the whole Chapter 11 procedure as well as for each round. Probabilities are given for the base case and for deviations from the base case as one bankruptcy-specific parameter value is changed at a time. 


\begin{tabular}{lccc}
\hline \hline Authors & $\begin{array}{c}\text { Sample } \\
\text { size }\end{array}$ & $\begin{array}{c}\text { Sample } \\
\text { period }\end{array}$ & $\begin{array}{c}\text { Average } \\
\text { value }\end{array}$ \\
\hline Panel A: Liquidation rate & & \\
\hline Denis and Rodgers (2007) & 224 & $1985-1994$ & $18 \%$ \\
Kalay, Singhal and Tashjian (2007) & 459 & $1991-1998$ & $20 \%$ \\
Bris, Welch and Zhu (2006) & 312 & $1995-2001$ & $24 \%$ \\
Carapeto (2005) & 389 & $1986-1997$ & $14 \%$ \\
Hotchkiss and Mooradian (2004) & 1,770 & $1979-2002$ & $21 \%$ \\
\hline Panel B: Time spent in Chapter 11 (in days) & & \\
\hline Denis and Rodgers (2007) & 224 & $1985-1994$ & 710 \\
Kalay, Singhal and Tashjian (2007) & 262 & $1991-1998$ & 447 \\
Bris, Welch and Zhu (2006) & 312 & $1995-2001$ & 822 \\
Elayan and Meyer (2001) & 146 & $1980-1995$ & 708 \\
Helwege (1999) & 57 & $1980-1991$ & 928 \\
\hline Panel C: Frequency of Absolute Priority Rule violations & \\
\hline Bharath, Panchapagesan and Werner (2010) & 531 & $1991-2005$ & $22 \%$ \\
Bris, Welch and Zhu (2006) & 312 & $1995-2001$ & $12 \%$ \\
\hline \hline
\end{tabular}

Table 6: Statistics about Chapter 11 filings reported by most recent empirical studies. 